\title{
PERIPECIAS DE UN TITULO: EN TORNO AL NOMBRE DE IA OBRA DE FERNANDO DE ROJAS
}

\author{
Erna Berndt Kelley \\ Smith College

\begin{abstract}
Quisiera dedicar este trabajo a la memoria de Clara Louisa Penney en el trigésimo aniversario de la publicación de su libro Book Called 'Celestina'.
\end{abstract}

Al reflexionar sobre varias obras literarias clásicas españolas el investigador se suele hallar desde un principio ante ambigüedades $\underline{y}$ cambios relaćionados con los titulos de las obras mismas. Basta recordar los problemas en torno a los ritulos del Cantar de Mio Cid, del Libro de Buen Amor y de Don Quijote de la Mancha. En algunos casos los manuscritos conservados carecen de titulos; en otros, los autores mismos llamaron a sus propias obras por varios nombres. A partir de la introducción de la imprenta, los impresores, interesados ayer como hoy en la venta de libros, habrán contribuido a que se incluyeran en los titulos $\underline{v}$ en las portadas elementos destinados a captar la imaginación del mayor número posible de lectores. Estos últimos $v$ los criticos, animados por la urgencia de abreviar titulos-normalmente extensos en su forma original--los redujeron o alteraron en forma tal que, a veces, nos dejan vislumbrar cambios de percepción de los que una obra na sido objeto en diferentes lugares $y$ distintas épocas.

Si bien el caso de la obra de Fernando de Rojas es conocido en cuanto a los cambios por los que pasó el título a través de los años, 1 creemos que es nora de detenernos para considerar la evidencia que nos queda y ver cómo, dónde y cuándo aparecen las alteraciones que han contribuído a que Ilamemos noy La Celestina al libro que comenzó por llamarse Comedia de Calisto y Melibea.

1. El testimonio de las ediciones de la Comedia de Calisto $\checkmark$ Melibea.

Dos de las tres ediciones en las que nos ha llegado la obra en dieciséis actos conservan la portada con el titulo. En la portada de la edición de 1500, impresa en Toledo por Pedro Hàgembach, aparece un grabado en el que se representa a los dos amantes en el jardin y, a la izquierda, a la vieja Celestina "llamando a la puerta. Debajo hallamos el siguiente titulo:

Comedia de Calisto \& Melibea: la // qual contiene demas de su agrada- // ble \& dulce estilo muchas sentenci--// 
as filosofales: $\dot{\&}$ auisos muy neces--// sarios para mancebos: mostrando // les los engaños que estan encerra // dos en siruientes y alcahuetas.

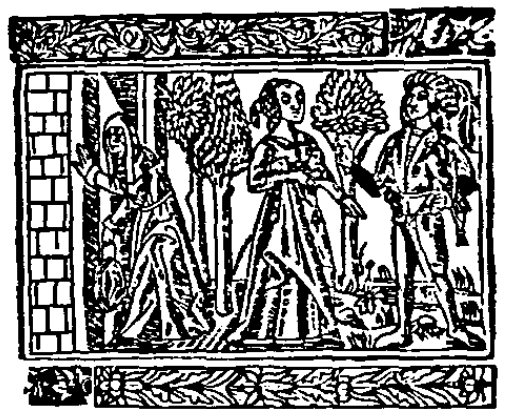

Comeós oe Califtor ADelibea:ls qual contiene oemas oe fuagraogs ble r oulce efthlo mucbasfentencis as filofofaleg:z suifoenurpecef fariosparamancebos:moftranoo leslosengañosque eftanencerta cosenfiruientesp alcsbuetas.

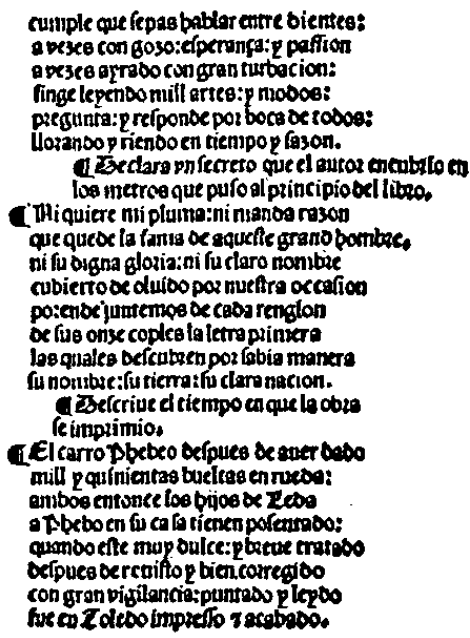

1. Portada y octavas finales de la Comedia, Toledo 1500 (Bib. Bodmeriana)

si bien los tres ejemplares de la Comedia que se han conservado contienen los argumentos de los dieciséis actos, solamente en la edición de Sevilla de 1501, impresa por Stanislao Polono, se anuncia la inclusión de los mismos en la portada, donde leemos:

Comedia de: calisto \& melibe(a). // $\operatorname{Co}(n)$ sus argume $(n)$ tos, nueuame $(n)$ te añadidos // La q(ua)l col $(n)$ tiene...2

2. Portada de la Comedia Sevilla 1501 (Bibliothèque Nationale Y.6310--Res. Yg. 63)

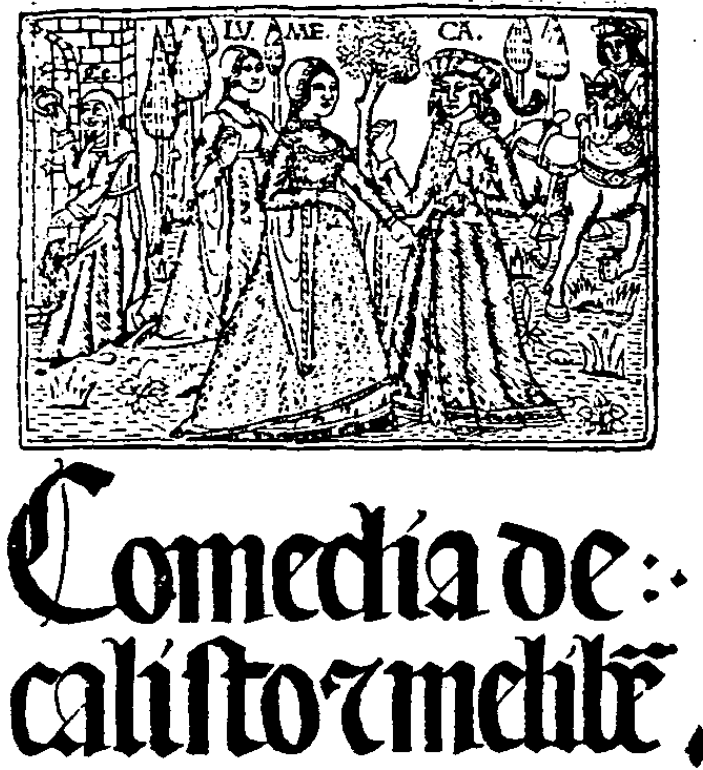

Só firs argumétos nucuamére añaoioos

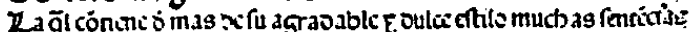

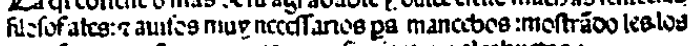

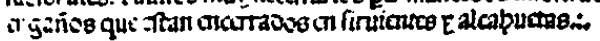


Tanto la edición de Toledo como la de Sevilla contienen la carta "El autor a vn su amigo" en la que "el autor" se refiere a "la p(re)sente obra," a "(e)stos papeles" y a "su p(ri)ncipal hystoria: o ficio(n) toda ju(n)ta" calificándola. de "obra discreta." Juntando la letra primera de cada verso de las once coplas que, según Alonso de Proaza, el autor puso "al principio del libro" $y$ en las que encubrió "vn secreto," leemos que "Elbachj11 Erfernan Doderoya Sacabola Comediad Ecalysto Ymelybea Yfvenasc Jdoenlap Uebladem Ontalvan." (La bastardilla es mía.) En los versos mismos se vuelve a mencionar varias veces "la obra," se habla del "dulce cuento," de "obra tan alta" y se la considera "obra de estilo tan alto \& sobido. 3 En ambas ediciones se repite el titulo en el texto que comienza "Siguese la comedia de calisto \& Melibea...." se anuncia el "Argumento del primer auto desta comedia" 4 , en el subtítulo de las octavas fina-

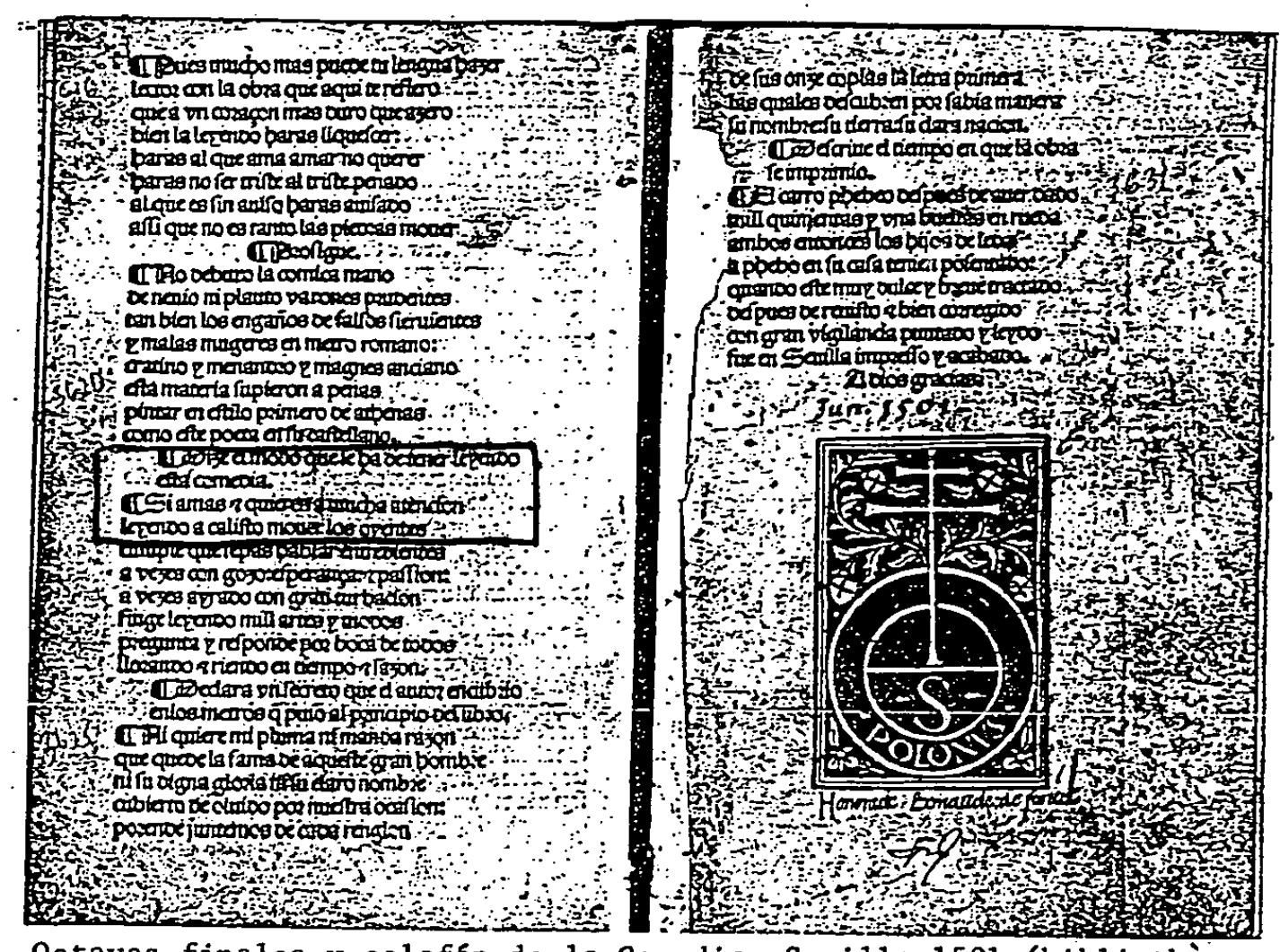

3. Octavas finales y colofón de la Comedia, Sevilla 1501 (bibliothèque Nationale, Y.6310--Res. Yg. 63)

les de Alonso de Proaza, se nos "Dize el modo que se ha de tener leyendo esta comedia." (La bastardilla es mía.) Es en la octava que sigue donde aparece va otro nombre con el que se ha de llamar ocasionalmente la obra de Fernando de Rojas. Leemos:

Si amas \& quieres a mucha atencion

leyendo a calisto mouer los oyentes... 
De modo que se habla de "esta obra" en términos generales; de esta "comedia" en términos-genéricos, Dor considerarse obra dramática, y mientras el libro lleva impreso el titulo de Comedia de Calisto $v$ Melibea, también se nombra ya la obra simplemente Calisto.

2. El nombre de la obra en veintún actos en las ediciones impresas en España hasta 1633.

Cuando Fernando de Rojas amplía la Comedia de Calisto y Melibea, le añade un prólogo en el que nos informa que su obra habia "seydo instrumento de lid o contienda a sus iectores." Entre otros aspectos -nos dice- también se había litigado sobre el nombre. No se disputaba la inclusión del nombre de los amantes, $\mathrm{ni}$ el de Celestina, sino si debiera llamarse Comedia o Tragedia en vista de su trágico fin. Al autor no le sorprende el hecho de que su obra sea "cosa que de tantas maneras se entienda" $y$, en un gesto salomónico que no deja de velar un poco de condescendencia hacia los lectores criticos, nos dice que queriendo "partir por medio la porfia" decidió llamarla Tragicomedia.

De la Tragicomedia se han podido localizar unas cincuenta $Y$ ocho ediciones impresas en España en el siglo XVI $y$ en el XVII hasta 1633. Se ignora el paradero de unas treinta más, citadas en distintos lugares. Ha sido imposible hasta ahora localizar ningún ejemplar de la obra en veintiún actos en lengua española, impresa en España con anterioridad a la aparición en Roma en 1506 de la traducción italiana de "alphonso hordognez nato hispano."6 Como se sabe, gracias a ia información proporcionada por $F$. J. Nortón, 7 ia edición de Zaragoza de 1507, cuyo impresor fue Jorge Coci, es la más temprana de las ediciones que nos quedan del texto español de la Tragicomedia. El único ejemplar conservado carece de portada. Comienza con "Siguese la Comedia o Tragicomedia de Calisto Y Melibea..."

4. Primera página conservada y última página de la edición de Zaragoza impresa por Jorge Coci en 1507. Bib. de la Real Academia de la Historia, Madrid $(3-7-2 / 3566)$

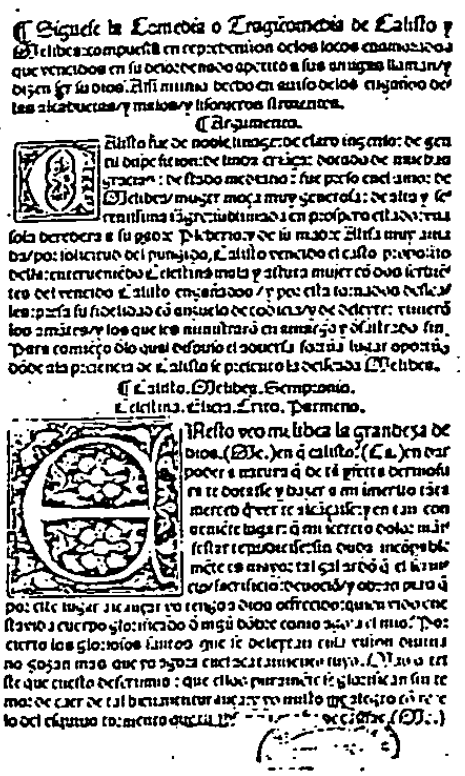


Al final del libro, en las octavas de proaza--como en las ediciones de la Comedia de Toledo, 1500 y de Sevilla, 1501-se menciona "la obra" y se habla del "libro." Se cambia la palabra "comedia" en el subtitulo de las octavas finales donde ahora se nos "Dize el modo que se ha de te--// ner leye(n)do esta Tragicomedia," cambio que se mantendrá en las siguientes ediciones de la obra impresas en España. También se siguen incluyendo los versos en los que se le instruye al lector cómo ha de leerse a Calisto.

Entre los años 1510-1514 los sucesores de Hagembach ${ }^{8}$ imprimieron en Toledo una edición para cuya portada utilizaron el mismo bloque--salvo barras diferentes--del grabado usado en la ilustración de la portada de la comedia de 1500. He aquí la portada:

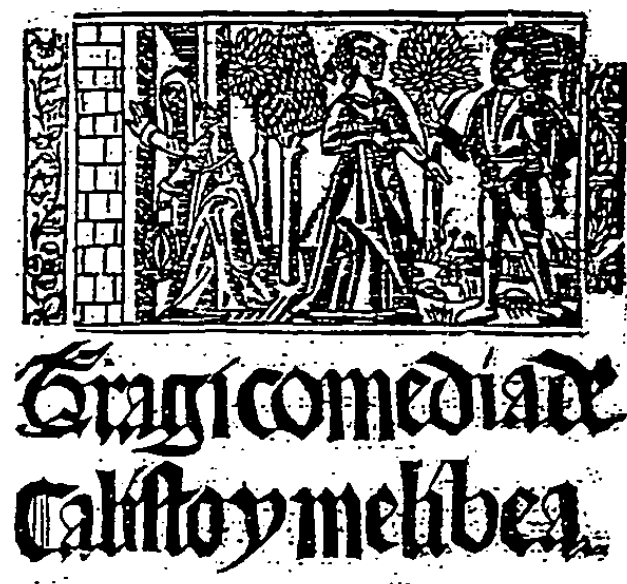

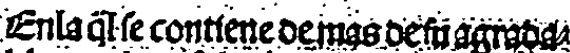

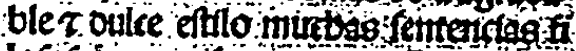

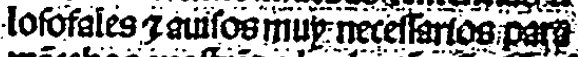
mácebos miofträo oles losieganofa a täencerrooosen ferifietes $r$ alcabuetas inueia mente anjoibo al tractao o de Centurio:
5. Portada de la edición de Toledo, 1510-1514, impresa por los sucesores de Hagembach (British Library C.20. b.9)

Observemos dos cambios en el subtitulo: 1) mientras que en los ejemplares de la Comedia con portada se lee: "la qual contiene demas de su agradable \& dulce estilo muchas sentencias filosofales..." en este ejemplar de la Tragicomedia hallamos: "Enla q(ua)l se contiene de mas de su agrada--// ble \& dulce estilo muchas sentencias $f i$ // losofales...;" y 2) al ínal del subtítulo se añade: "\& nueua mente añadido el tractado de Centurio," pues a lo que Fernando de Rojas denominaba la "nueva adicion," a los actos añadidos que constituyen el alargado "processo de su deleyte destos amantes," se llama aquí y se llamará en las portadas de varias de las subsiguientes ediciones, "tractado" 0 "tratado de Centurio." 


\section{CELESTINESCA}

Los mismos cambios que observamos en el titulo $y$ subtitulo de la edición toledana de los sucesores de Hagembach los hallamos también en el único ejemplar conservado de la edición de Sevilla de hacia 1511, impresa por Jacobo Cromberger $y$ en otra, supuestamente también suya, que apareció también en Sevilla entre 1513 y 1515, excepto que, en el subtítulo de esta última leemos: "Enla q(ua)l se contiene(n) d(e)mas $d(e)$ su agradable \& dulce estilo muchas sente(n)cias filoso i/ fales..." corrección que se mantendrá en el subtitulo de la gran mayoria de las ediciones posteriores de la Tragicomedia impresas en España. ${ }^{9}$

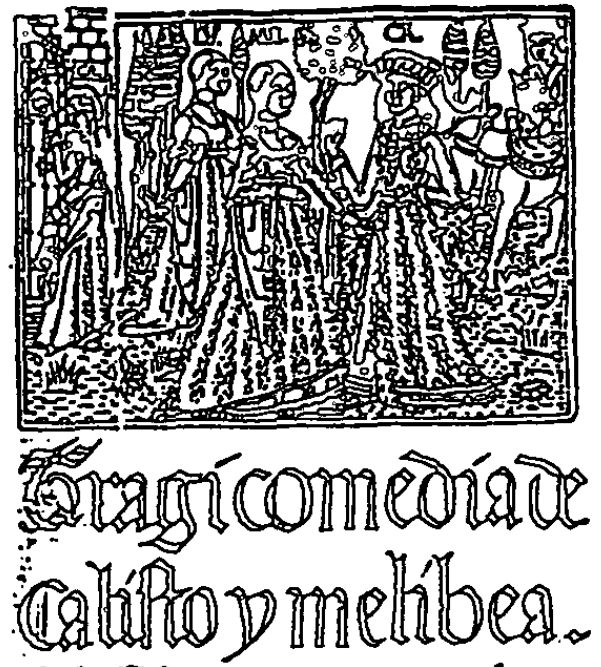

Enlaquic cōticne demas de fuagra osbler oulceeftilo mucbas fentécias filofofales:r auifos mur necettarios pamäcobos:mortrandóles los ngs ños queftsnencerrados en feruientes zaleabuetas. z nuellamête añadido cltractado ve centurio.

6a. Portada de la edición impresa en Sevilla por Jacobo Cromberger h. 1511 (Brit. Library C.20.c.17)

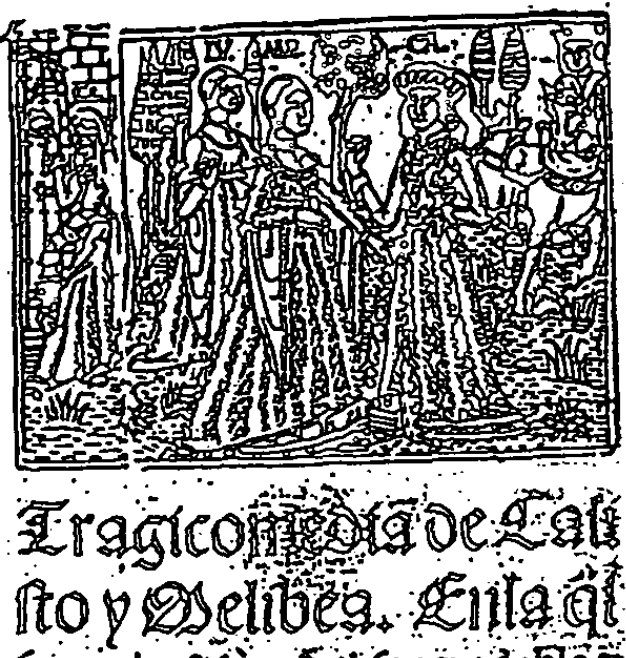

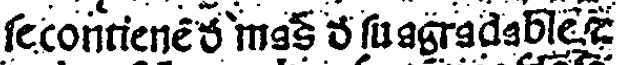

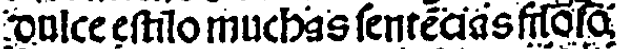
hales: guifosmun neceffarios pars: mácebos:monträdoles los êgaños âftainencerrgdos en ferutétes $\tau$ at cabtutgs. Enveüámente sinadido êtrigțdo oc centritio.

6b. Portada de la edición impresa en Sevilla por Jacobo Cromberger 1513-1515 (Dept. Rare Books and Special Collection, U. Michigan)

En 1514 Juan Joffre imprime en valencia su famosa edición con la siguiente conocida portada: 

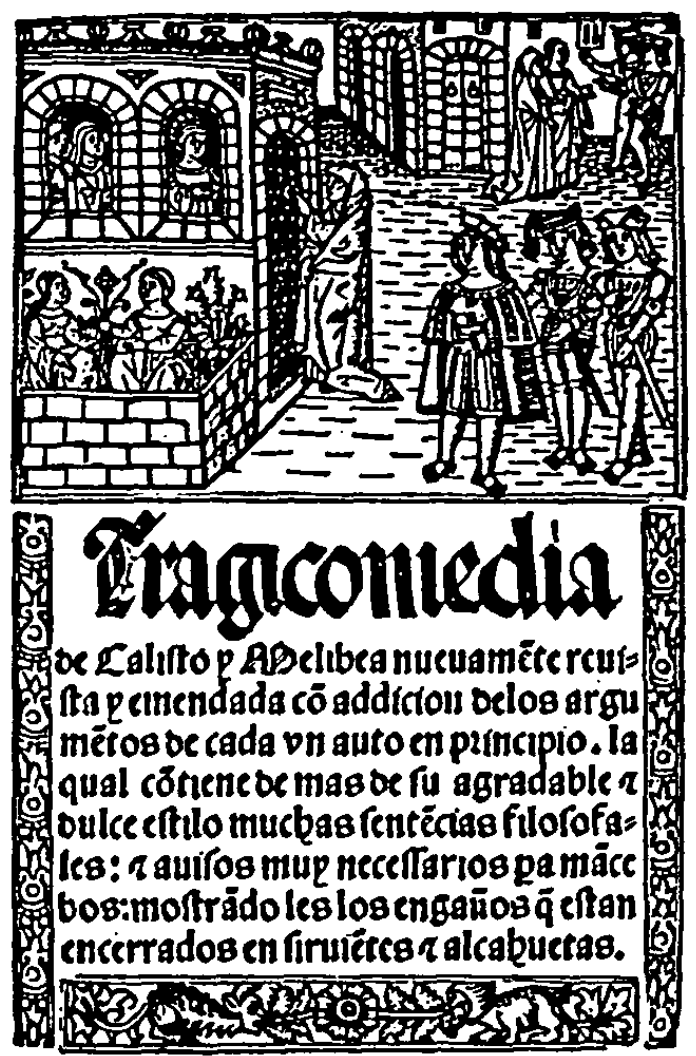

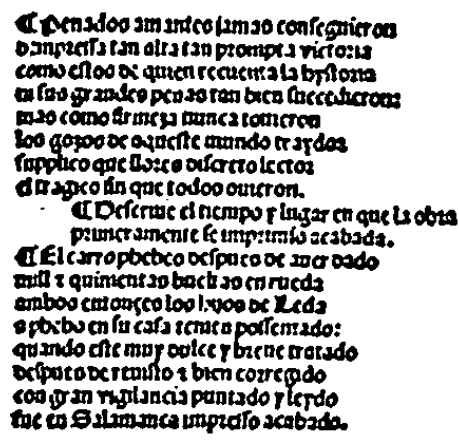

TEragicomedia be Ralitorme libea.2Igora nuevainente reuis Ata $r$ courcgida conlos argu mentos oc cada auto en paincipio acabaffecon olligenciaftudioim pectia cnlai ifigna cilidad oc vislectia por 3 uli joffre a.tri.ocfelute rosc.LID. Q.D.P.t.tiij aînos.

7. Portada y Gltima página de la edición de Valencia impresa por Juan Joffre en 1514 (Biblioteca Nacional, Madrid, R/4870)

En esta ocasión a los actos añadidos no se les da el nombre "tratado de Centurio," en cambio, inmediatamente después del título "Tragicomedia de Calisto y Melibea" se nos informa que esta edición fue "nueuame $(n)$ te reuista $y$ emendada $c o(n)$ addicion delos argume $(n)$ tos de cada vn auto en principio." En lo demás sigue en el subtítulo el contenido de las ediciones de la Comedia de Toledo, 1500 y de la de Sevilla, 1501: "la qual co(n)tiene de mas de su agradable \& dulce estilo muchas sente(n)cias filosofales..." En estas peculiaridades le siguen también las ediciones de Valencia, $1518^{10}$ del mismo Juan Joffre $y$ de Valencia, 1529 impresa por Juan Viñao. 11

Entre 1518 y 1520--según Norton--se imprime en el taller de Jacobo cromberger en Sevilla una edición de ía Tragicomedia con un título muy abreviado: "Libro de Calixto v // Melibea y de la pu-// ta vieja Celestina." 


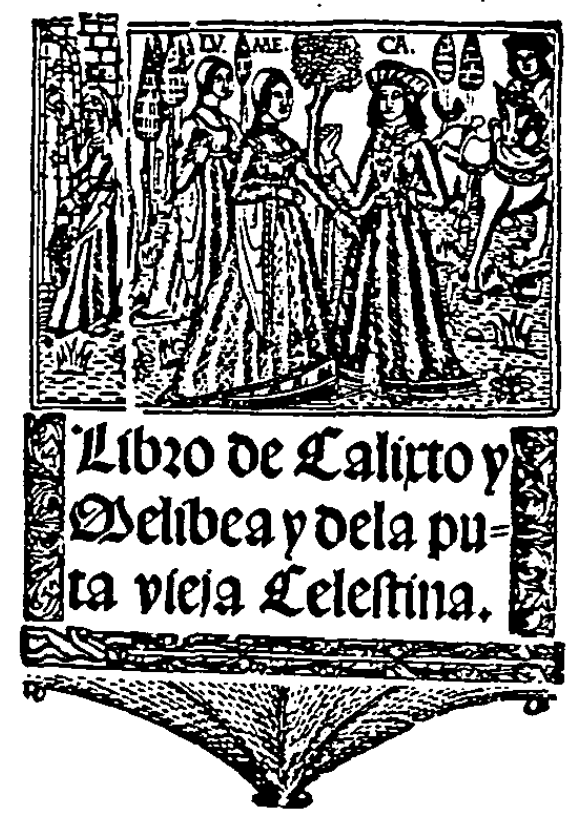

8. Portada de 1a edición de Sevilla '1502', impresa por Jacobo Cromberger entre 1518 y 1520 (Biblioteca Naciona1, Madrid, R/26575)

Si bien esta edición parece haber servido de base a numerosas ediciones posteriores de la Tragicomedia, en España no fue imitada en cuanto a su titulo original. Como veremos, mientras que el nombre de Celestina aparece a partir de 1519 y de 1527 regularmente como título en las portadas de las traducciones italianas $Y$ francesas respectivamente, el nombre de. la medianera no se volverá a imprimir hasta mucho más tarde como título en las portadas de las ediciones impresas en España, donde el título sigue siendo Tragicomedia de Calisto y Melibea.

De la imprenta de Jacobo Cromberger alemán $y$ Juan Cromberger se nos han conservado dos ediciones más de la Tragicomedia: i) la de sevilla, $1525^{12}$ en la que vemos que los impresores han vuelto al título y subtitulo empleados en las dos ediciones anteriores ya citadas, impresas por Jacobo Cromberger en sevilla, que anunciaban en la portada la inclusión del "tractado de centurio;" y 2) la de Sevilla, 152813 en la que se suprime dicha información de la portada pero que, en cambio, se da al final del libro donde leemos:

"Acabasse la Tragicomedia (conel tratado de Centurion) con diligen/// cia corregido y emendado. Impresso por Jacobo Cromberger alemam i $i$ v Juancromberger. Año del señor de M.d.xxviij. en fin de Março."

La adición del "tratado de Centurio" se anuncia también en el subtitulo de la edición impresa por Carlos Amorós en Barcelona, 1531 y en las portadas de las ediciones que contienen el "Auto de Traso"14 que se discutirán a 
continuación. En todas las demás ediciones publicadas en España hasta 1633, de las que se han conservado ejemplares, dicha información se relega al íinal del librol5 o se omite por completo.

\subsection{Ediciones con el "Auto de Traso"}

En 1526 sale de la prensa de Remon de Petras en Toledo una edición de la Tragicomedia con el "Auto de Traso," innovación que se anuncia en la portada.

9. Portada y colofón de la edición de Toledo 1526, impresa por Remon de Petras (British Library C.63.f.25)
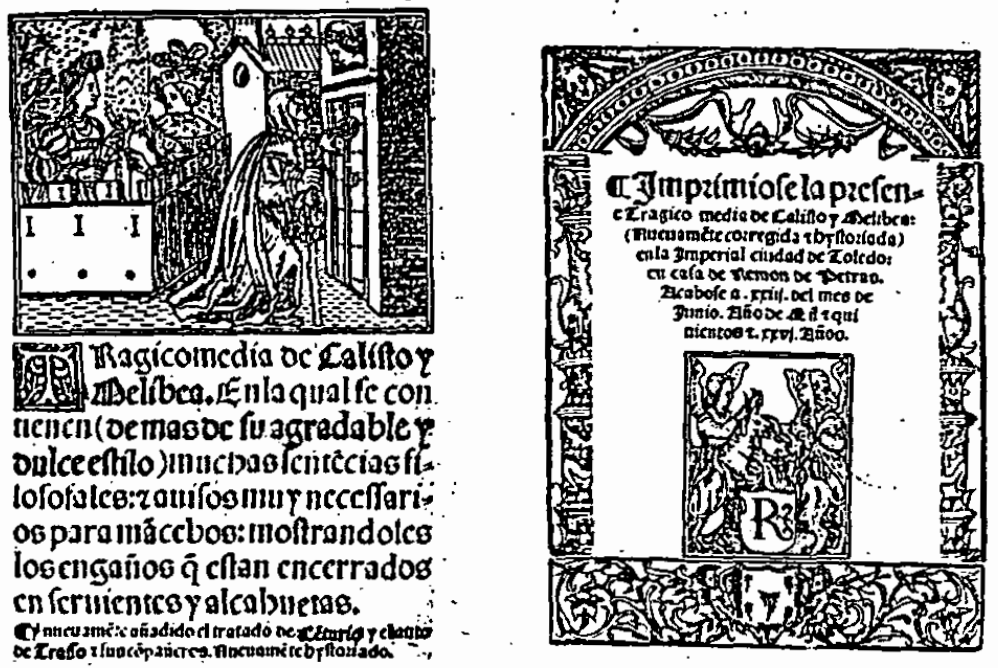

Efectivamente, incluye como acto diecinueve el "Auto de Traso" ampliando Ia Tragicomedia a veintidós actos. Entre 1530 v 1540 se publica en Medina del Campo otra edición con el acto añadido cuyo impresor elimino el subtítulo acostumbrado reduciendo la información de la portada a "Tragicomedia de Calisto y Meli-//, Dea. Conel tra // tado $d(e)$ Cen // turio y /i el auto de Traso.."

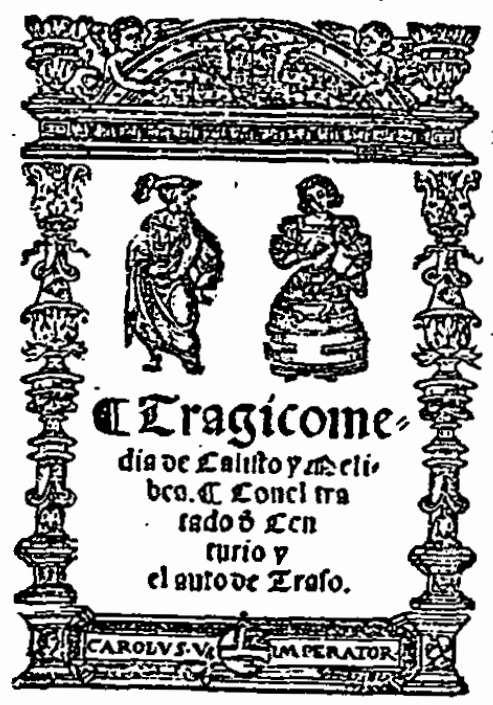

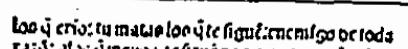

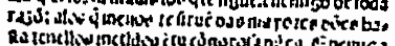

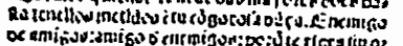

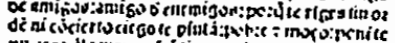

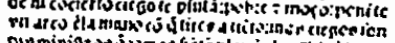

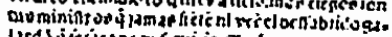

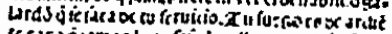

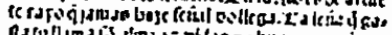

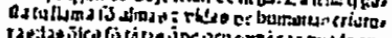

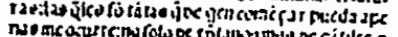

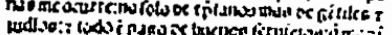

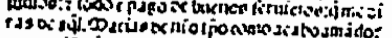

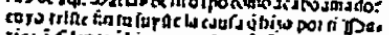

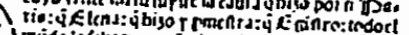

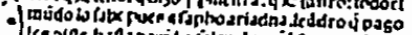

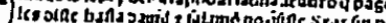

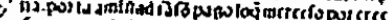

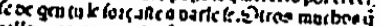

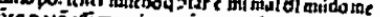

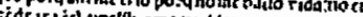
A.

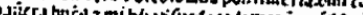
enouda:

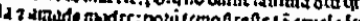

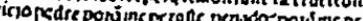

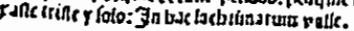

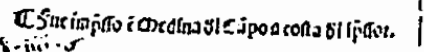

10. Portada y última página de la edición impresa en Medina del Campo entre 1530-1540 (Biblioteca Naciona1, Madrid, R/3801) 
En cambio Juan de Ayala en Toledo, en su edición de 1538-también de veintidós actos--vuelve a incluir el subtítulo que aparece en la gran mayoría de las portadas de las ediciones de la Tragicomedia añadiendo: "Co(n)el tra // tado de Centurio y el auto de Traso." 16

La inclusión del "Auto de Traso" como acto diecinueve del texto de la Tragicomedia parecía haber sido una característica Iimitada a las tres ediciones que se acaban de mencionar. 17 Sin embargo, los recientes hallazgos de Clive Griffin $y$ de Ivana Gallo $y$. Emma Scoles ${ }^{18}$ nan demostrado que hubo por lo menos tres más en una serie de ediciones impresas en España entre 1526 y 1560 que ampliaron el texto de la Tragicomedia a veintidós actos $y$ que anunciaron el "Auto de Traso". en sus respectivas portadas.19

2.2 La aparición de "Celestina" como nombre de la obra.

En el año 1561 Claudi Bornat adopta una costumbre que ya se habia puesto en práctica antes en Amberes, a saber, la de encabezar las páginas del libro por "Tragicomedia" (en verso) y "de Celestina" (en recto).20 Ese encabezamiento lo hallamos también en las páginas de la edición de Carlos de Lauayen y Iuan de Larumbe de Zaragoza, 1607:

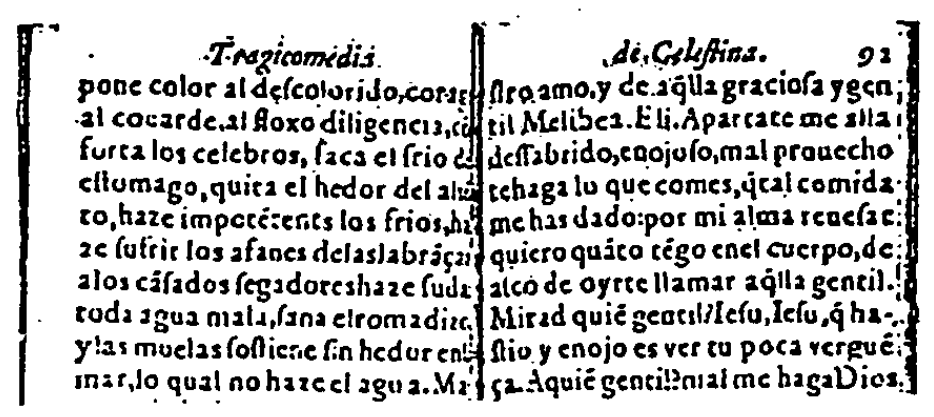

11. Páginas 91 y 92 de la edición de Zaragoza 1607 impresa por Carlos de Lauayen y Iuan de Larumbe (Oesterreichische Nationalbibiothek 38 L 96)

No obstante, el título en la portada de estas ediciones sigue siendo Tragicomedia de Calisto y Melibea.

En 1569 se imprime en Alcalá en casa de Juan de Villanueva una edición en cuya portada, encima del título T $R$ A G I C O // MEDIA DE CALIS- // to $\mathrm{y}$ Melibea, seguido del acostumbrado subtítulo, leemos en tipo de imprenta muy pequeño $y$ entre corchetes: [CELESTINA]. 21 


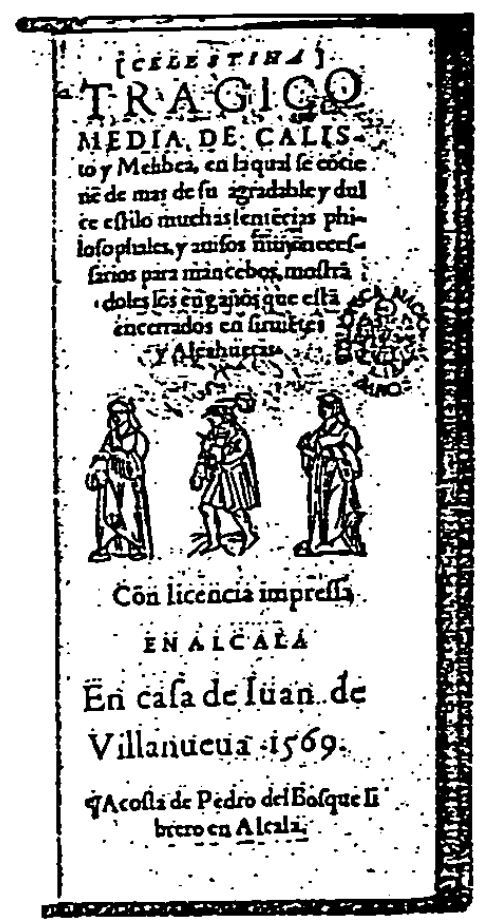

12. Portada de la edición impresa en Alcalá 1569 (Bib. Nacional, Madrid, $\mathrm{R} / 31686$ )

Es la primera $y$ única vez--después del caso del ya mencionado titulo original de la edición de sevilla, 151820--que aparece el nombre de la medianera en el título de la portada de una edición de la Tragicomedia publicada en España en el siglo XVI. En todas las demás ediciones impresas en España hasta 1631, de las que se han conservado ejemplares con portada, aparece el título como rragicomedia de Calisto Y Melibea.

\subsection{El nombre de la Tragicomedia en las licencias, tasas y aprobaciones.}

Si los impresores no se animaban a llamar la obra de Fernando de Rojas por el nombre de la medianera en las portadas, los obispos, provisores generales, escribanos y secretarios que firmaban las iicencias, a veces, si la Ilamaban Celestina.

Si bien a partir de la promulgación del decreto del 7 de septiembre de 1558 se les obligaba a todos los impresores a que incluyeran, en el material preliminar a ias obras que imprimían, las licencias obtenidas del Consejo de Castilla, son numerosas las ediciones conservadas que carecen del 
texto de las licencias aun cuando, como ocurre en varios casos, se anuncie en las portadas de los libros que los permisos fueron obtenidos. 22 con todo, las licencias, tasas $\checkmark$ aprobaciones que muchas de las ediciones contienen, reflejan los diversos nombres por los que se conocía la obra de Fernando de Rojas. En el ejemplar de la edición de Cuenca, 1561, por ejemplo, leemos:

"Por la pressente doy licencia y facultad a vos Juan de Canoua ympressor de libros, esta(n)te en esta ciudad de Cuenca, pare [sic] que podays imprimir \& imprimays la celestina primera." $23^{\circ}$

Consultando la edición de Medina del Campo, 1566, nos enteramos de que Francisco del Canto había pedido la licencia para publicar la obra de Rojas:

"... nos fue hechà relacion, diziendo que vos queriades imprimer el libro, intitulado Celestina primera..." 24

Una leve variación del título la nallamos en la iicencia de la edición de Salamanca, 1569 de Mathias Mares, otorgada en Madrid el 23 de diciembre de 1568:

"... vos teniades en vuestro poder vn libro intitulado Celestina ia primera. El qual con licencia nuestra se auia impresso otras vezes..."25

Mientras tanto, en la licencia de la edición de Alcalá, 1569 de Juan de villanueua, en cuya portada, como va hemos observado, se imprimió timidamente "[CELESTINA]" encima del título corriente, hallamos:

"... auiendo se visto por los señores del consejo Real de su magestad vn libro que se presento por parte de Iua(n) de Villanueua impressor de libros, vezino de la villa de Alcala intitulado primera Celestina se mando que se le diesse licencia..." 26

Los que firmaban estas licencias la llamaban "primera" para distinguir ia Iragicomedia de Fernando de Rojas de las imitaciones que habian aparecido durante la primera mitad del siglo XVI, como la Segunda Celestina, 1534, de Feliciano de Silva; la Tercera parte de la tragicomedia de Celestina, 1536, de Gaspar Gómez de Toledo; Y la Tragicomedia de Lisandro $v$ Roselia Ilamada Elicia v por otro nombre cuarta obra y tercera Celestina, 1542, de Sancho de Muñino.

En las licencias. Y tasas de numerosas ediciones del resto del siglo XVI se sigue insistiendo en que ia obra se titulaba Tragicomedia de Calisto $v$ Melibea 27 Pero si bien se la nombró así en la iicencia de la edición de Salamanca, 1590 [i.e. 1591] de Iuan y Andres Renaut, impresa a costa de Claudio Curiet, Licencia obtenida en iadrid en diciembre de 
1574, en la "tassa," fechada en Madrid el 24 de enero de i591, leemos :

"Yo Miguel de Ondarça çauala escriuano de camara del Rey nuestro señor de los que residen en el su consejo, doy $f e$ que hauiendose visto por los señores del vn libro intitulado Calisto, $y$ Melibea, que nizo imprimir Claudio Curlet, con licençia de su Magestad, tassaron a cinco blancas el pliego." 28

No es hasta 1581 que en una licencia--en ia otorgada a Francisco del Canto para ia edición que imprimió en 1582 en Medina del Campo--se llama al libro simplemente Celestina:

"... vos $q($ ue)riades imprimir vn libro intitulado
celestina... vos damos licencia..."29

Así se nombrará la obra de Fernando de pojas en las licencias de varias ediciones subsiguientes. 30 También se da el caso en que en la iicencia aparece el libro "intitulado Tragicomedia de Calisto y Melibea," mientras que en la tasa de la misma edición se nos informa que "tassaron vn libro intitulado Celestina." 31 Esta ambivalencia se expresa en la licencia que encontramos en la edición de Zaragoza, 1607, de Carlos Lauayen y Iuan Larumbe:

"Sabed, que auiendose suplicado por vuestra parte os mandemos dar iicencia para boluer a imprimir vn iibro va impresso intitulado Tragicomedia de Calisto $y$ Melibea, vulgarmente intitulado, Ei libro de Celestina..." 32

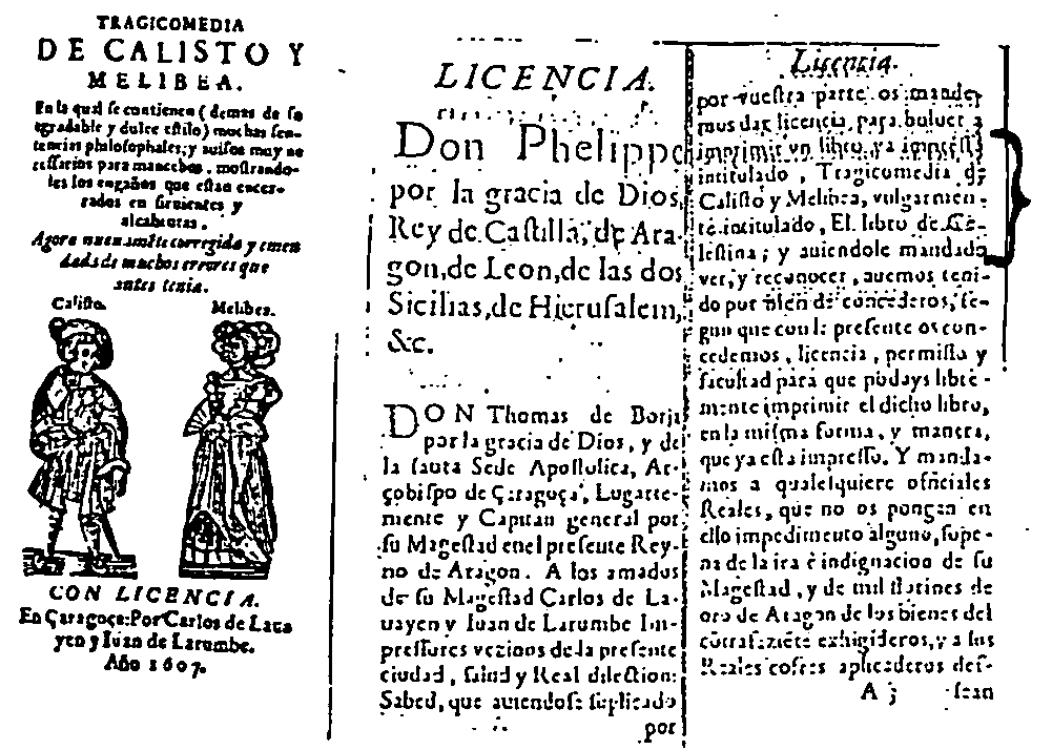

13. Portada y licencia de la edición de Zaragoza 1607 impresa por Carlos de Lauayen y Iuan de Larumbe (Oesterreichische Nationalbibliothek 38-L-96) 
aclaración que no impidió que a partir del folio a-10-v en adelante las páginas de esta edición quedaran encabezadas, como va hemos señalado, por "Tragicomedia" (en verso) v por "de celestina" (en recto). 33 Finalmente los impresores de ia edición de Madrid, 1632 (in fine: 1631), habrán creído oportuno el que se resumiera v reflejara lo esencial de la problemática en torno al título de la obra de Fernando de Rojas en la portada, ya que en ella el titulo aparece: "TRAGICOMEDIA // D E C A L I S T O // Y MELIBEA, VVLGAR-i/ mente llamada Celestina..."34

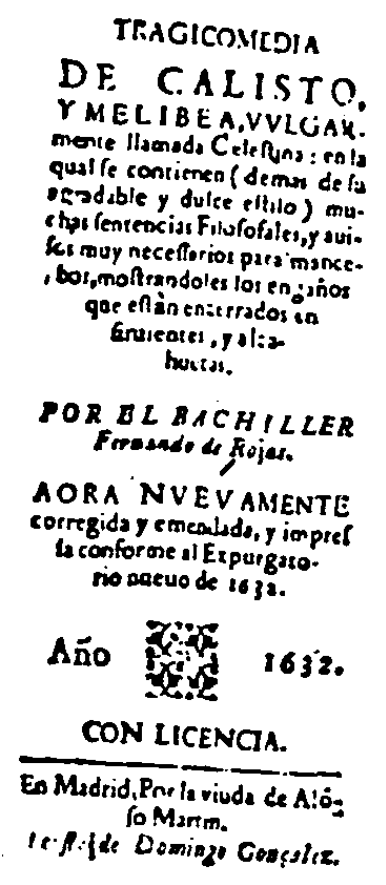

14. Portada de la edición impresa en Madrid 1632 [in fine: 1631] por la viuda de Alonso Martín (Hispanic Society of America).

pero observemos, los que firmaron la suma de licencia, la suma de tasa y la aprobación de esta edición, tal vez por no querer formar parte del "vulgo," seguian llamando a ia obra Tragicomedia de Calisto y Meiibea.

3. El titulo de las ediciones impresas en Italia.

\subsection{De las traducciones.}

En 1506 salió de la imprenta de "Eucharium Silber alias Franck" en Roma la edición de la traducción de "alphonso nordognez nato nispano." el texto más antiguo de la Tragicomedia que se ha conservado. Se basa, desde luego, en una edición perdida del texto español. Aparece con el 
título siguiente: "TRAGICOMEDIA DI CALI // STO E MELIBEA NOVAMEN if TE TRADVCTA DE // SPAGNOLO IN // ITALIANO // IDIOMA." 35

15. Portada y colofon de la primera traducción. italiana de la Tragicomedia impresa en Roma 1506 (Houghton Library, Harvard University, *SC5/R6382C/Ei 5060)
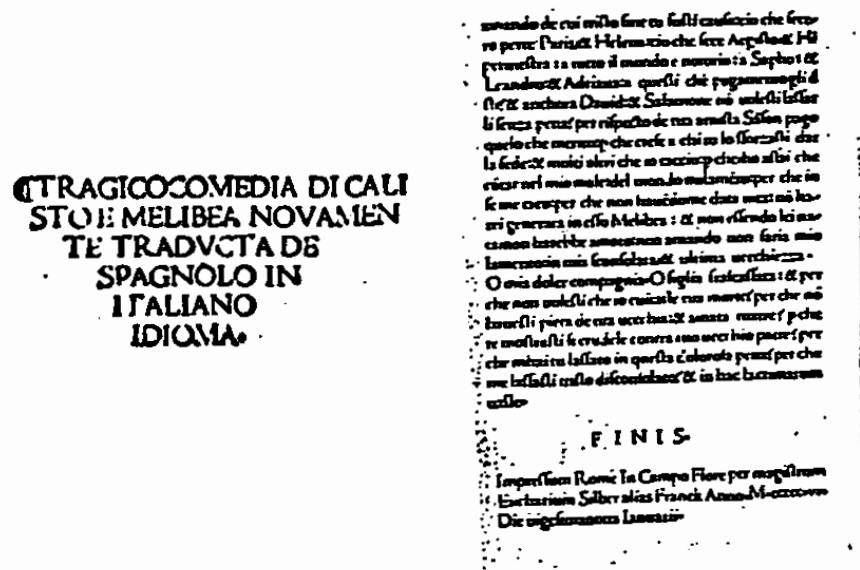

Casi el mismo título lo siguen manteniendo zanotto da Castione en la portada de su edición fechada el 23 de junio de 1514,36 Vincenzo Minuziano
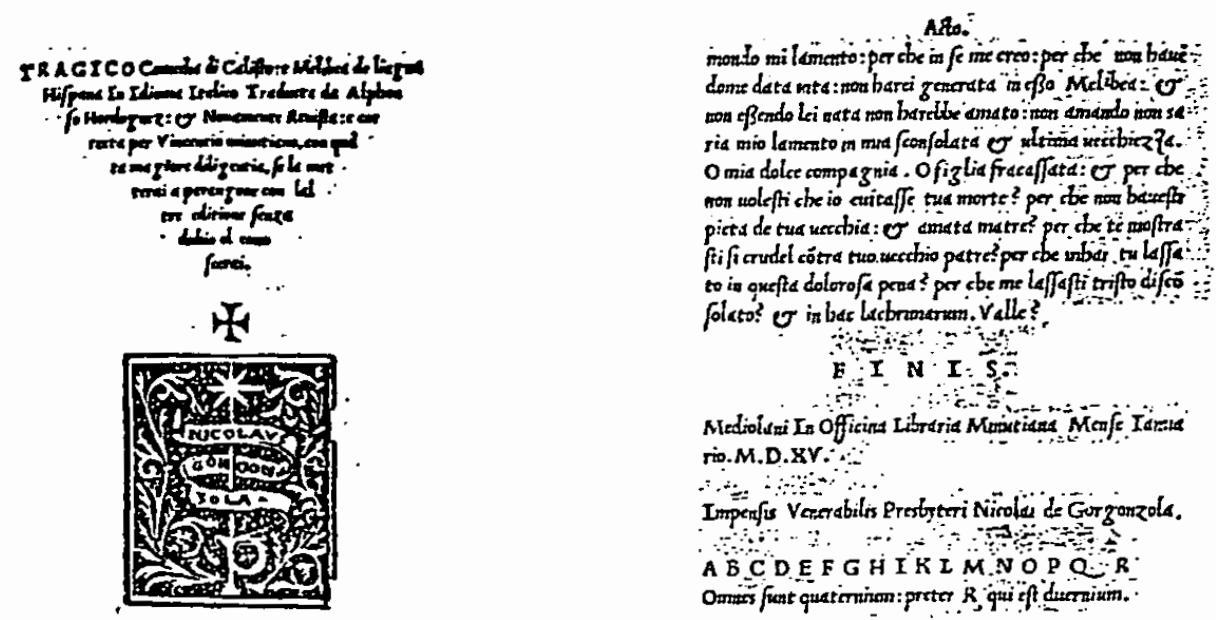

16. Portada y colofón de la traducción italiana de la Tragicomedia impresa en Milán 1515 (Houghton Library, Harvard University *SC5/6382 c/ Ei 506oc) 
en la suya de Milán de enero, 1515,37 P. Pincius (si es que efectivamente fue el impresor) en la de Venecia con fecha 12 de abril de 1515,38 y Angelo Scinzenzeler en la suya de marzo $16,1519.39$

En 1519 Cesaro Arriuabene publica en Venecia la primera edición de la Tragicomedia--ya sea del texto en español o en italiano--que lieve en la portada el titulo de celestina seguido de Tragicomedia de Calisto \& Melibea.40 En la portada de esta traducción italiana se hace alarde del hecho que se halle "adorna // da etiam d(e) molte bellissime figure." En efecto, además

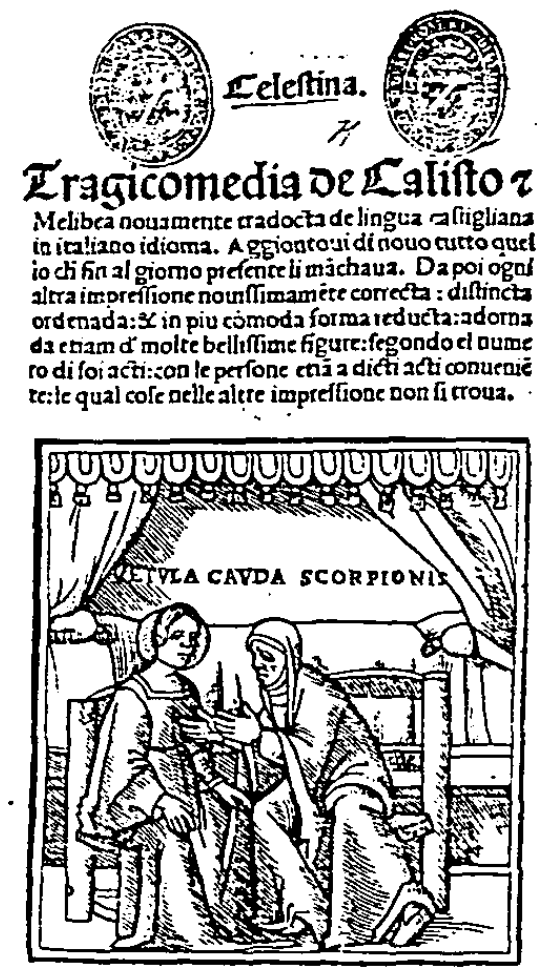

Cxxvill

CL Einiffe la traçicomedia intitclatacalsfo $\alpha^{*}$ mells bex:tradoets de lingua spagnola in italianc. idioma: nouninere contecta a da ogui error calligatz. Agion toui turto quello li manehaua: $x$ adurnada de mole belliffitne figure:alli acti se materie conueniznte. Iria preffa cō gran diligent:a in uenctia pet Céaro amiua beno cenitsano nelli anni del notitu lugnote wille ar, quecento e diliausue a di diexe decembrio. Regilio.

Tutti fonoquatterni.

A BC.DEEGHIKL M NOPQ

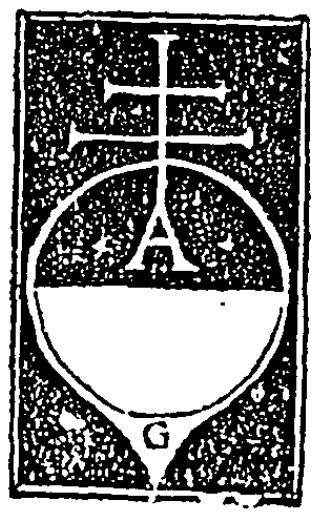

93 cil.

17. Portada y colofón, traducción italiana impresa por Cesaro Arriuabene el 10 de diciembre 1519 en Venecia (British Library 11726.aa.20)

de Iniciar la costumbre de llamar "Celestina" en la portada a Ia obra de Fernando de Rojas, esta edición llama la atención por el grabado de la portada, pues nasta entonces se habian representado más bien las íiguras de ios amantes rodeados de algunos otros personajes de la obra, incluso Celestina. Aqui, en cambio, tenemos solamente a Celestina $y$ Helibea, a ia vieja medianera practicando sus artes, enredando a ia joven enamorada. Encima de las dos figuras aparece la inscripción "VETVLA CAVDA SCORPIONIS", aludiendo al conocido diálogo entre pármeno y Celestina en el primer acto. No cabe duda que con esta portada se quería Ilamar 


\section{CELESTINESCA}

atención al personaje de celestina con sus actividades. Desde entonces en adelante las ediciones

\section{CELESTINA}

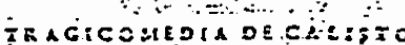

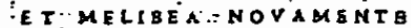

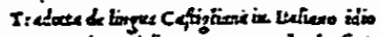

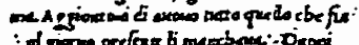

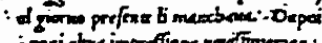

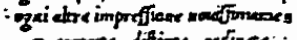

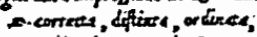
Vo in pia conmoda from - mdiex, $\therefore$ ace....

itegind of note d:

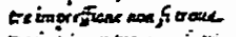

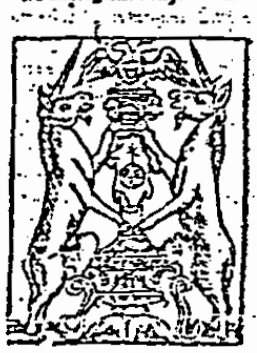

18. Portada, traducción italiana impre-

sa en Venecia 1525 por Francesco Caron. (Charles Patterson. van Pelt Library, U. de Pennsylvania 868 R63C .IO)

19. Portada, traducción italiana impresa en Venecia 1531 por Marchio Sessa? (Thomas Fisher Rare Book Library, U. of Toronto. B-10 381)

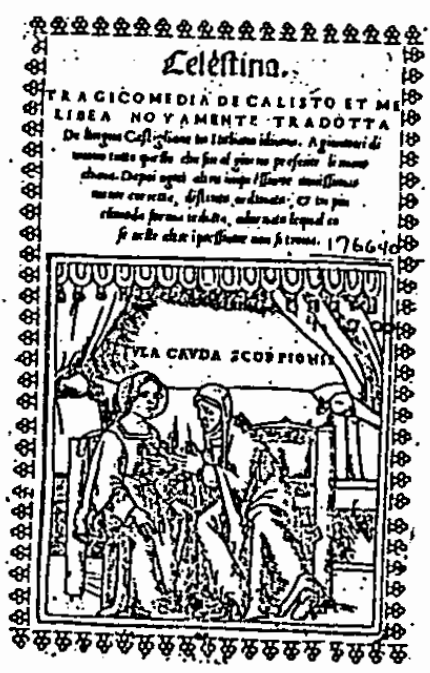

de todas las traducciones italianas aparecerán con el titulo Celestina, bien visible, como puede verse consultando los ejemplares de las traducciones antiguas conservadas. 41

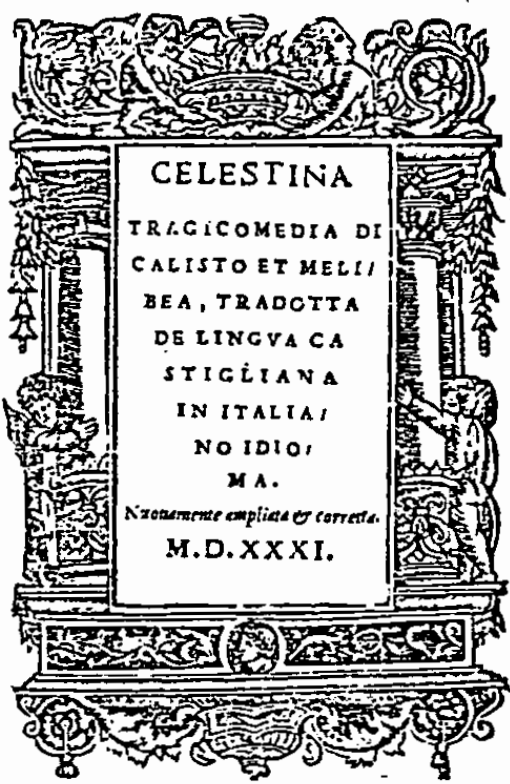

20. Portada de 1a traduccion italiana impresa en Venecia 1531 por A: Bindoni $\&$ M. Pasini

21. Portada de 1a traducción italiana impresa en Venecia 1543 por Bernardino de Bendoni (Special Collections, Van Pelt Library U. de Pennsylvania--

SC5 R8382 Ei505o)

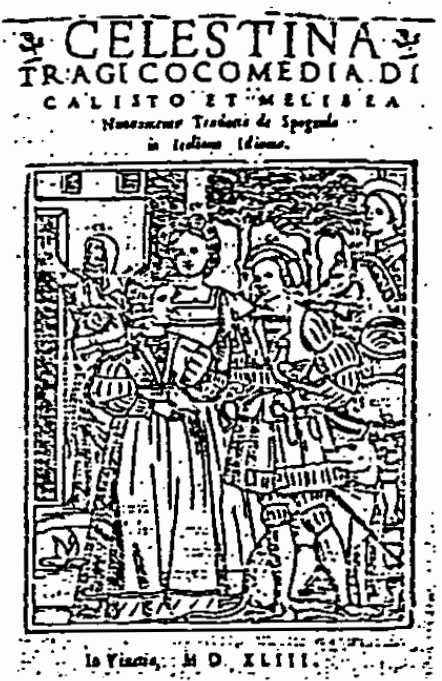


3.2 De las ediciones del texto español.

Mientras que a partir de 1519 con la edición de Venecia, impresa por Cesaro Arrivabene, las portadas de las traducciones italianas aparecen encabezadas por el título de Celestina, ios impresores de todas ias ediciones del texto en español impresas en Italia en el siglo dieciséis, se abstienen de incluir ese título en las respectivas portadas, es decir, siguen ilamando la obra Tragicomedia de Calisto y Melibea, continuando asi la costumbre de los impresores españoles: He aquí las portadas de dos de las nueve ediciones del texto español, impresas en Italia, de las que se han conservado ejemplares:

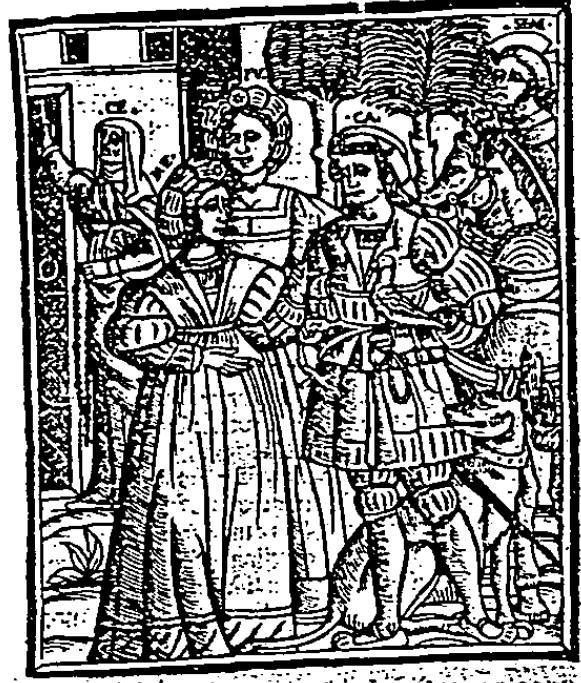

Eragicomedia oe Ealifto

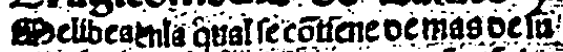

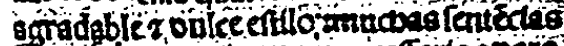

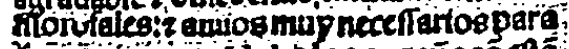

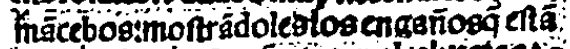
encertados in Feruientes $z$ alcabuetas: $z$

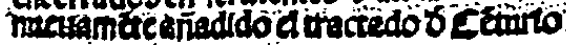

22. Portada de ía edición del texto español impresa en Venecia 1534 por Estephano da Sabio (Hispanic Society of America)
23. Portada de la edición del texto español impresa en Venecia 1553 en casa de Gabriel Giol to de Ferrari y sus hermanos (Coleccion privada de J. T. Snow)

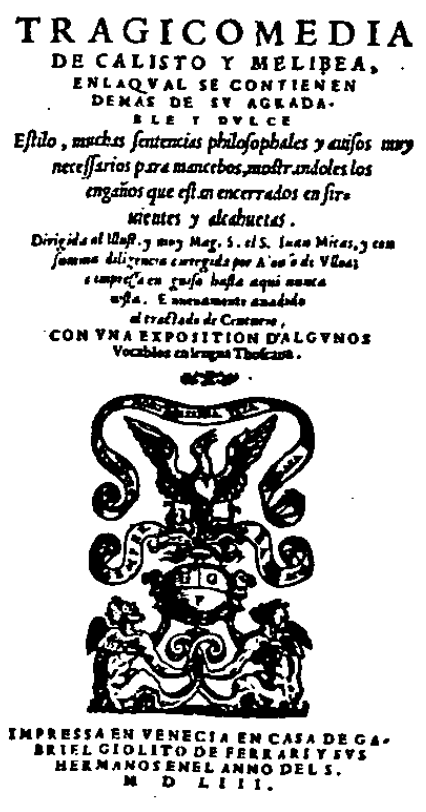

No es hasta 1622 que se publica en Milán una edición del texto español con el título CE L E S T I N A: 


\section{CELESTINESCA}

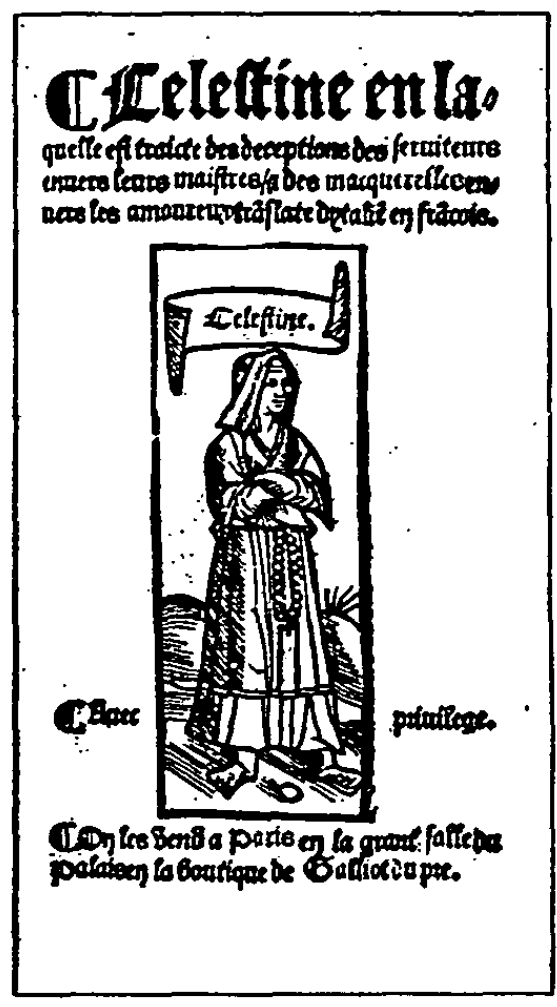

24. Portada de la primera edición de 1a traducción francesa de Paris 1527 (Biobliothèque Nationale, París, Res. Yg. 307)

El personaje de la alcahueta habia captado la imaginación del público lector italiano en tal modo que los impresores en Italia, mientras respetaban el titulo que Fernando de Rojas había dado a su obra y lo empleaban en sus ediciones del, texto en lengua original, para sus traducciones se tomaron la libertad de entitularlas Celestina. En las portadas de estas traducciones el título original quedaba reĺegado a un segundo término para formar parte del extenso subtítulo.

\section{El titulo en las traducciones francesas.}

En 1527 se publicó en Paris ia primera traducción francesa de la Tragicomedia. Como demostró Gerard J. Brault, 42 aunque en la portada se da la impresión de que fue traducida del italiano al francés, el anónimo traductor utilizó, además de la traducción italiana, una edición del cexto español como base de su iraducción, pero observemos que, en cuanto al titulo, los que prepararon la portada para ia traducción francesa siguieron el ejemplo de la traducción italiana $y$ no el de la edición del texto español llamándola Celestine. También en el privilegio de esta primera 
25. Portada de la edición de1 texto español impresa en Milán 1622 a costa de Iuan Baptista Bidelo Librero (Hispanic Society of America)

\section{CELEST INA \\ Tragıcomedia \\ D E. \\ CALISTO Y MELIBEA.}

Inla fasl fe costienen de mas de fo agradablo ydulce eflilo, muchus fententias filofofales. Y auifos muy oeceferios para mancebos.

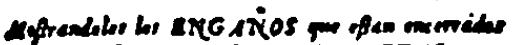
- SIRYIENUES alcahrETAS.

All Illufrifirmo Señor Conde Ąntonio Vifcoste Conde de Lonato Pocolo.

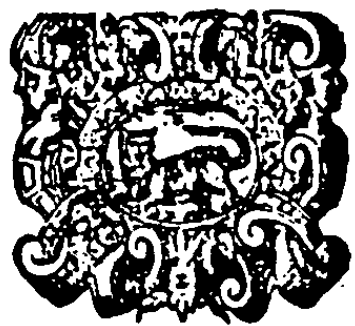

EN MILAN.

A culla de luan Baprifts Bidelo Librero M. DC. $\times \times 1$ I.

traducción francesa se le permite a Gaillot du Prè, al iibrero de la universidad de París, nacer imprimir $\mathrm{V}$ vender el presente "livre de Celestine..."43 $\mathrm{El}$ nombre de los amantes se elimina por completo del título v la ilustración de la portada con una Celestina que pisa recio, con los brazos cruzados y las cuentas colgadas de las manos, no deja lugar a duda que para los que prepararon esta edición, la medianera era el personaje principal de la obra. En Francia el nombre de ia alcahueta aparece en el titulo de todas ias traducciones que se publicaron hasta 1644.

Con ia publicación de la segunda traducción francesa, ia de Jacques de Lavardin, impresa en Paris, en 1578, se inicia entre los impresores franceses la costumbre de llamar la obra La Celestine, título que seguirá apareciendo en todas las portadas de las traducciones francesas. 44 Además, por lo menos dos ediciones de esta segunda traducción--de la que hubo varias--, la de Paris de 1578 y otra sin fecha pero posiblemente del mismo año--de cuya portada incluimos 


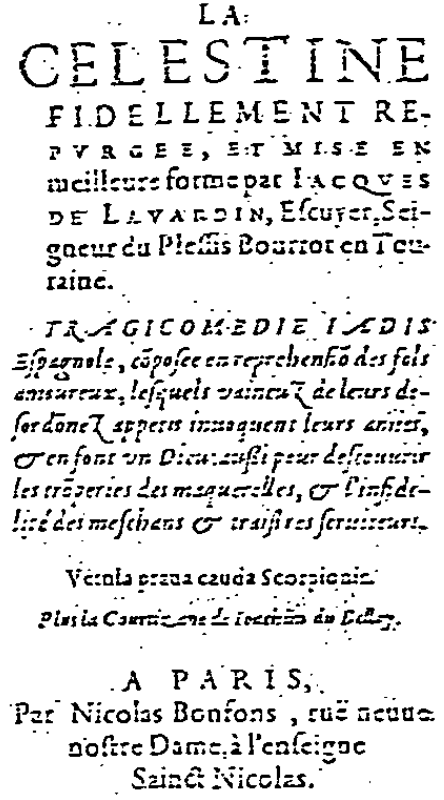

26. Portada de la traducción francesa impresa en París posiblemente en 1578 por Charles Bonfons (Special Collections, Van Pelt Library, University of Pennsylvania SC5 R6382 Eh5601 1578)

un racsímil-, presentan debajo del titulo $y$ extenso subtítulo el epiteto latino "Vetula praua cauda scorpionis". ya aparecido en varias portadas de ediciones italianas y con el que se expresaba la opinión que se tenía del personaje cuyo nombre eclipsó el de ios amantes en el título de todas las traduciones francesás.

Cuando en 1633 se prepara en Rouen una edición bilinguie español-francesa, basando esta vez la traducción en un texto español, mientras se opta por el título de TRAGICOMEDIA // DE CALISTO // Y MELIBEA, VVLGAR- // MENTE LLAMADA CELESTINA para la versión española, para la traducción francesa se invierte el orden colocando LA CELESTINE en primer lugar:

27. Portada de 1a edición bilingüe impresa en Ruan 1633 por Charles Osmont (Hispanic Society of America)

\section{TR AGICOMEDIA DE CALISTO Y MELIBEA, VVLGAR. MENTE LLAMADA CELESTINA:

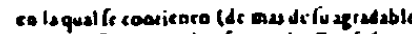

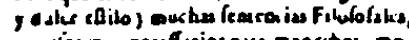

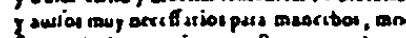

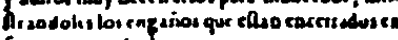

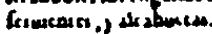

20ACLAACHILLER friendo do Rore.

CORRECIDA Y EMENDADX

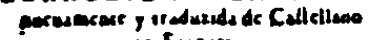
co fisoict.

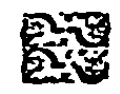

E $N$ R A N

1611
IA CELESTINE $0 \mathrm{~V}$ HISTOIRE TRAGICOMIQVE DE CALISTEET DE AELI OEE.

Compoféc en Elpañol, par le Bachelicr Fcrous Rojes.

E! rrataise de soneses an Frangon:
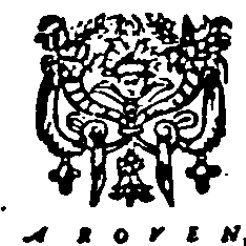

Cher Chaslas Osmont; cóle grande rü̈ des Carmes.

M. D C x x 1 .

$A S C P A I Y I L E C E$. 


\section{CELESTINESCA}

Estos titulos se repetirán en las ediciones bilingües de Rouen-Pamplona, 1633; Rouen 1633-34 y de Rouen 1644.45

5. El título en las ediciones de la Tragicomedia impresas en los Países Bajos.

A partir de 1539 un buen número de ediciones del cexto español de la Tragicomedia salió de los talleres de las prensas en los Países Bajos. La primera de estas ediciones fue la de Guillaume Montano con fecha 28 de junio de 1539.

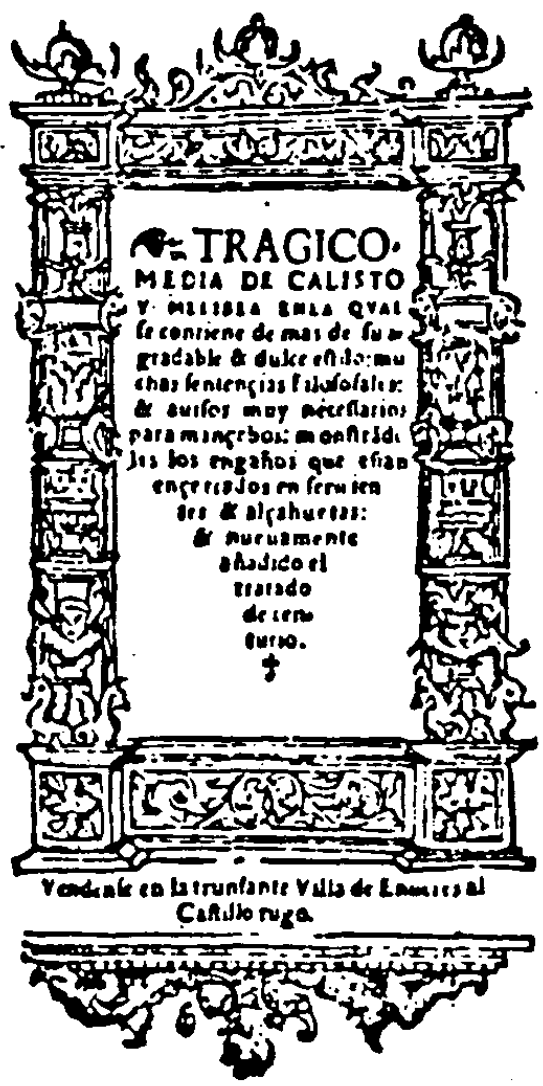

28. Portada de la Tragicomedia impresa en Amberes 1539 por Guillaume du Mont (Hispanic Society of America)

Como señaló Theodore Beardsley, 46 esta edición siguió muy de cerca la tradición de las ediciones venecianas del texto español, especialmente la de 1534, imitándola fielmente tambièn en cuanto al título. 


\section{CELESTINESCA}

En igual modo, Martín Nucio en las dos ediciones suyas de las que se han conservado ejemplares, publicadas en 1544 y 1545 respectivamente, imprime la obra con el titulo Tragicomedia de Calisto y Melibea.

Con la edición de la viuda de Martín Nucio, impresa en Amberes en 1558, parece haberse iniciado la costumbre de encabezar las páginas del libro con "TRAGICOMEDIA" (en verso) y "DE CELESTINA" (en recto), si bien observamos que en la portada el titulo sigue siendo Tragicomedia de Calisto $v$ Melibea. 47 Esto lo repetirá Philippo Nucio en 1568,48 después de asumir las reponsabilidades del taller neredado de su padre. No es hasta 1585 que se publica en la famosa prensa de la oficina Plantiniana el texto de la Tragicomedia en una edición con el título Celestina, Tragicomedia de Calisto y Melibea. 49 En 1595 se publica otra edición en el mismo taller con una portada que presenta en grandes caracteres mayúsculos el titulo "C E L E S T I N A" seguido de "Tragicomedia // DE // CALISTO Y MELIBEA" en letras de tamaño más pequeño. 50 Además observamos que en el subtítulo se destacan en caracteres mayúsculos las palabras "ENGAÑos", "SIRVIENTES" y "ALCAHUETAS", palabras con las que al parecer se quería llamar la atención al propósito didáctico de la obra. Todo ello se repetirá en las portadas de las dos ediciones que salieron de la misma prensa en 15.99.51

29. Portada de una de las ediciones del texto español impresas en 1599 en la Oficina Plantiniana (Colección privada de J. T. Snow)

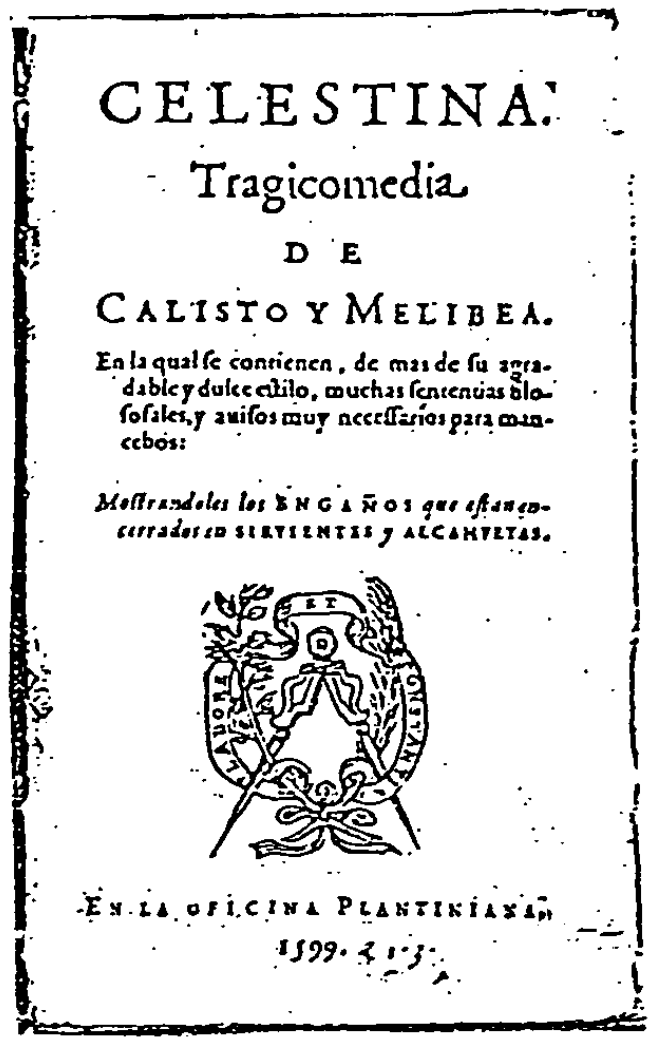


Desafortunadamente, de otra edición, también de la oficina Plantiniana, ia de 1601 , no se ha podido iocalizar hasta ahora ningún ejemplar. 52

Si en cambio volvemos nuestra atención a las traducciones flamencas, vemos que, si bien son menos numerosas que las italianas, también presentan mucho antes que las ediciones del texto español impresas en los Paises Bajos, el titulo de Celestina en sus respectivas portadas.
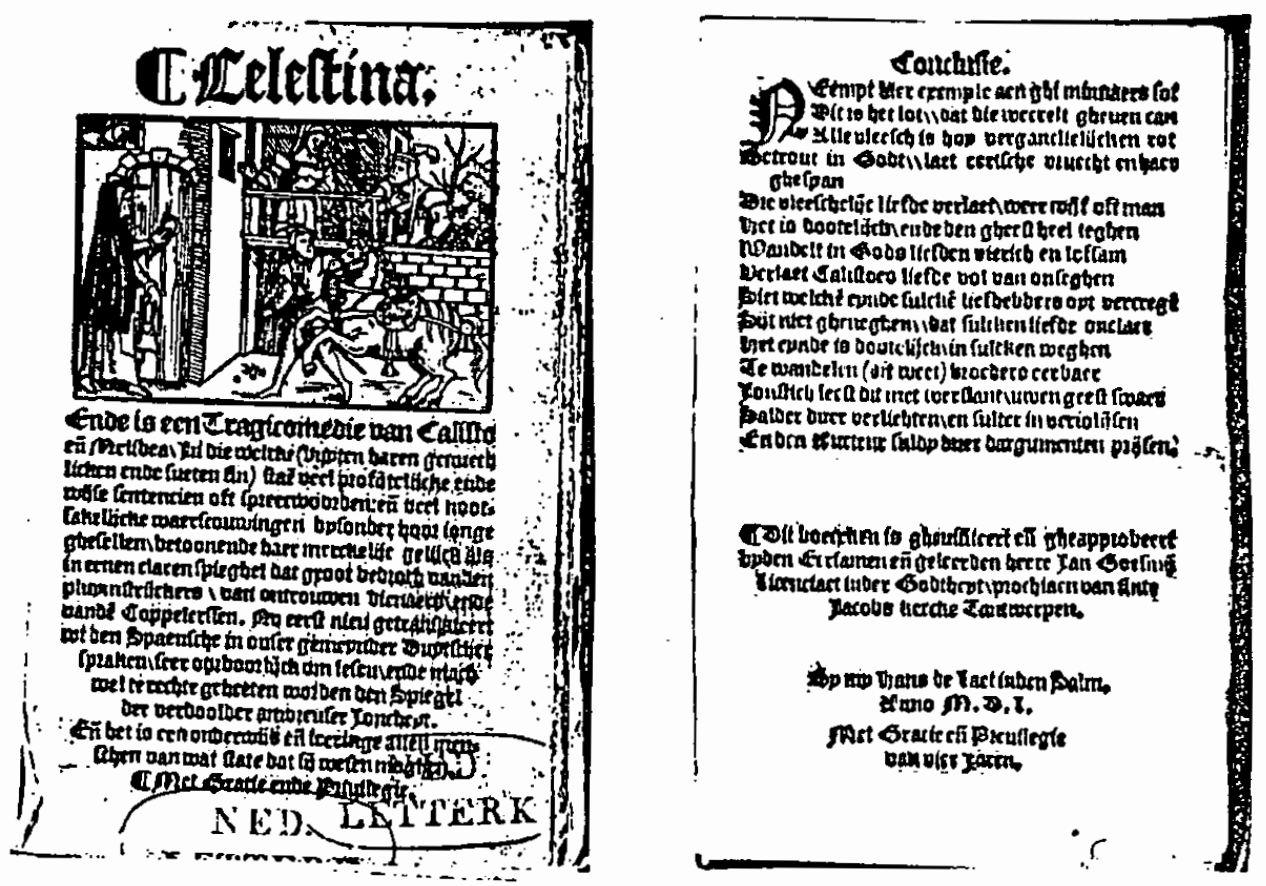

30. Portada y colofón de la traducción flamenca impresa por Hans de Laet, Amberes 1550

No obstante se elimina de la portada de la edición de Heyndrick Heyndricx de Amberes, 1574, para las demás traducciones se vuelve a usar el título de Celestina, seguido de "Een tragicomedie van Calisto ende Melibea..."

6. El iitulo de la obra de Fernando de Rojas en Inglaterra y Alemania.

6.1 El título de la Tragicomedia en Inglaterra.

La primera adaptación de la Tragicomedia en lengua inglesa, de hacia 1530, lleva el siguiente incipit:

A new cõmodye in englysh in maner /

of an enterlude ryght elygant \& full of craft

of rethoryk / wherein is shewd \& dyscrybyd as

well the bewte \& good propertes of women / 
as theyr vycys \& euyll cõdiciõs / with a morall cõclusion \& exhortacyon to vertew. 53

El nombre de Celestina no aparece en el mismo ni tampoco el de los amantes. Sin embargo, casi todas las referencias a la obra, tales como "Comoedia Celestina" (1566), "A booke entituled Lacelestina Comedia in Spanische" (1591). V "The tragick Comedye of Celestina" parecen indicar que el nombre de la medianera iormaba parte del título por el que se conocia ta tragicomedia en Inglaterra en el siglo dieciséis. 54
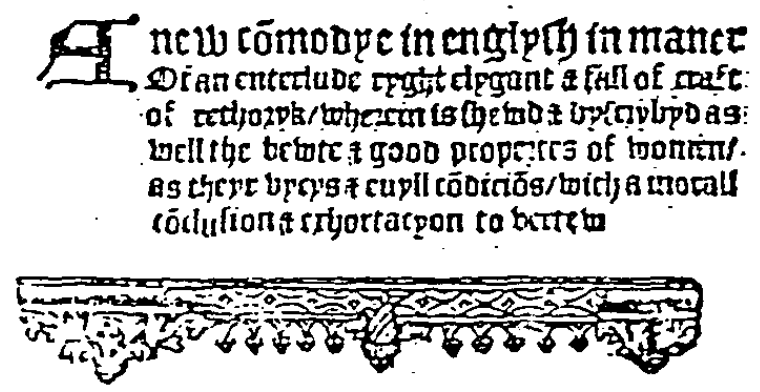

31. Incipit de la primera adaptación inglesa (los primeros cuatro actos) por un autor anónimo (Bibliotheca Bodleiana--0xford)

En el manuscrito de Alnwick de la traducción de James Mabbe, editado $y$ estudiado por la investigadora Martínez Lacalle. que como ella sugiere, na de fecharse entre los años 1603 y 1611,35 el hispanista inglés parece haber seguido muy de cerca una de las ediciones del texto español impresas en la Oficina plantiniana, también en cuanto al titulo de "CELESTINE $/ /$ or the TRAGICKCOMEDIE // of CALISTO and MELIBEA,..."j6 En la epístola dedicatoria que contiene este manuscrito, se refiere varias veces al libro como Celestine $^{j 7} \mathrm{y}^{\circ}$ eventualmente, aclarando para los lectores

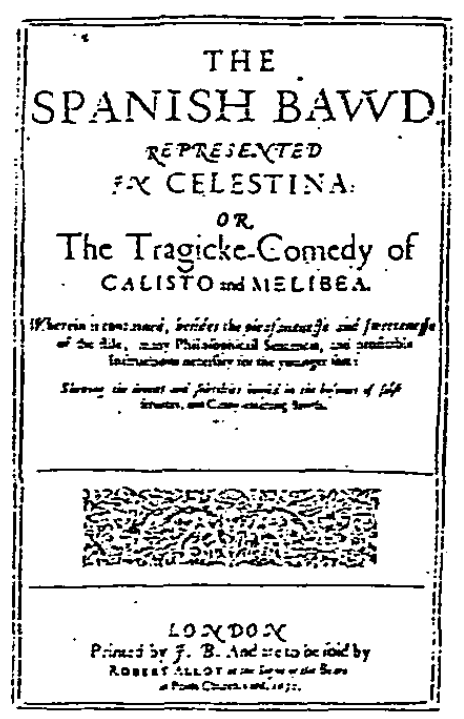

32. Portada de la traducción inglesa de James Mabbe impresa por J[ohn] B[eale] en Londres 1631 (Hispanic Society of America) 


\section{CELESTINESCA}

ingleses quién era Celestina, publica su traducción con el titulo "THE // SPANISH BAWD, // REPRESENTED // IN CELESTINA: // OR, // The Tragicke-Comedy of // CALISTO and MELIBEA."

\subsection{El título de las traducciones alemanas.}

El 20 de diciembre de 1520 se terminó de imprimir en el taller de Sigismund Grimm y Markus Wirsung en Augsburgo la primera traducción alemana de la Tragicomedia preparada por Christof Wirsung. 58 Como podemos observar en la portada. para el titulo el traductor alemán en lugar de "Tragicomedia" optó por "Hipsche Tragedia", incluyó el nombre de los amantes a quienes describe como un caballero $Y$ una noble doncella respectivamente, y le promete

33. Portada de la primera traducción a lemana publicada en Augsburgo 1520, Herzog August Bibliothek, Wolfenbüttel --L1 206 [Reproducido de la ed. facs 1mil "Die Celestina-Ubersetzungen von Christof Wirsung," Hildesheim/Zürich/ New York: Georg Olms Verlag, 1984]

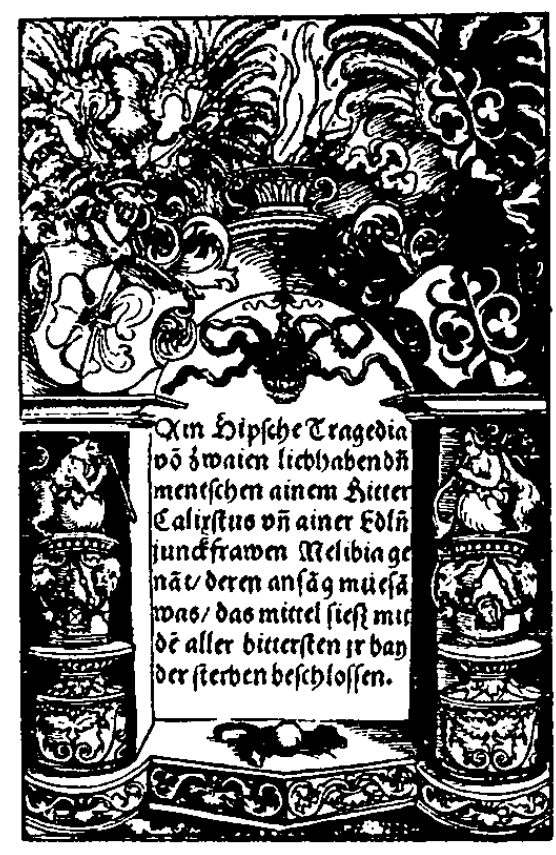

al iector una obra de dificultoso principio, dulce medio y del más amargo ín por la muerte de ambos. No aparece el nombre de la medianera. Si Wirsung se valió de la edición de Arrivabene, Venecia 1519, como Dase para su traducción, decidió no imitarla en cuanto a la novedad de llamarla Celestina.j9 En la "carta dedicatoria" menciona "ain biechlin ausz Hispanischer in lumbardish welsch gewendt", es decir, un librito traducido del español al italiano lombardo, afirma que el título lo identifica como una "Tragedia" Y explica que bien podria llamarse "Comedia", sin mencionar en ninguna ocasión el nombre de Celestina.60 Tampoco siguió el ejemplo de la edición de Arrivabene, ni campoco el de la traducción francesa de 1527,--ediciones que, como nemos señalado, llevan en la portada el título de Celestina $y$ Celestine respectivamente--cuando en 1534 
publica AInn recht Liepliches büchlin..., su nueva traducción

34. Portada de la segunda traducción alemana publicada en Augsburgo 1534, Universitätsbibliothek, Erlangen--RI 166 da [Reproducido de la edición facsímil "Die CelestinaUbersetzungen von Christof Wirsung" --Hildesheim/Zürich/New York: Georg Olms Verlag, 1984]

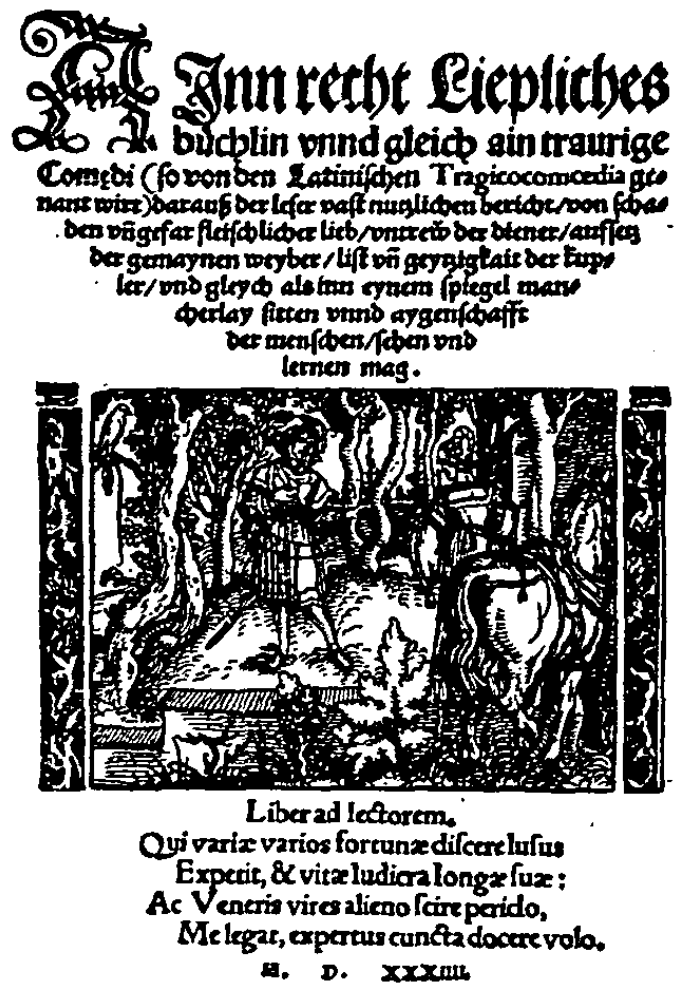

alemana, en la que el propósito didáctico es evidente comenzando por el extenso titulo.61 En el diálogo entre Urbanus $y$ Amusus que reemplaza la "carta introductoria" de la primera versión de wirsung, se vuelve a hablar del librito (büchlin)62 de este español ("disem Hispanier")63 cuya ficción ("gedicht") 64 se parangona con las obras de Séneca, de Plauto $\mathrm{y}$ de Terencio. También se habla de esta "Tragicomedia"65 y al evaluar a los personajes se menciona a la vieja alcahueta (alten kupplerin"),66 a esta mujer infame ("verleymtesten weybe") 67 y se condena la instigación de la vieja "Scelestina", 68 su ralsedad, su codicia, sus mentiras $\checkmark$ perversidad ("vntrew geytigkait lugin vnd boszheyt").69 Pero el nombre de la medianera no forma parte del título de las traducciones alemanas.

\section{7. "Vulgarmente Ilamada Celestina"}

Hemos resumido lo que hicieron los impresores en España, en Italia, en Francia $\underline{v}$ en otros paises europeos respecto al título de la obra de Fernando de Rojas. Pero. ¿cómo la Ilamaban en España los iectores que la discutían, la criticaban o simplemente la mencionaban? Al principio, al parecer, se la llamaba por varios nombres. 
En el proceso contra Aluaro de Montaluan, en el año 1525, el suegro de Eernando de Rojas--como señaló hace años Serrano v Sanz-- 70 identificó a su hija Leonor Aluares como "muger d(e)l bach(ille)r Rojas que compuso a Melibea."

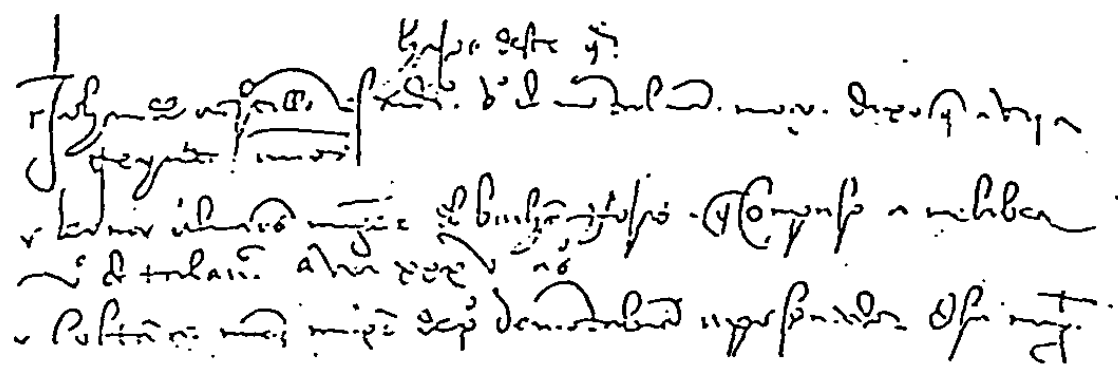

35. Facsímil (parcia1) del folio 4 del proceso de la Inquision de Toledo contra Alvaro de Montalbán [1525] donde se menciona a "Leonor alvares muger d[e]1 Bach[i11]er Rojas, q[ue] compuso a melibea ..."

Es interesante que naya sido el padre de la mujer de Rojas quien al mencionar a su hija le diera ese nombre a la obra de su yerno. Es caso ünico.

Al comentar la edición de la Comedia de Toledo, 1500, va vimos cómo Alonso de Proaza en ios versos de las octavas finales llamaba a la obra calisto. No se trata de un caso aislado. En ia edición del Libro del emperador Marco aurelio $c o(n)$ relox de principes impreso por maestre Nicolas Tierri en Valladolid en 1529, Antonio de Guevara enumera a calisto entre los libros vanos con los que muchos pierden el tiempo, 71 si bien más adelante, en 1539, io ilamará celestina. 72

En el "Ynventario de los bienes y hazienda de juan cromberger difunto" fechado el 10 de septiembre de 1540, en la iista de iibros, se mencionan "262 Calistos" $y$ "63 Celestinas". 73 ¿De qué textos y ediciones se trataba? Juan Cromberger había heredado el taller de imprenta y la iibrería de su padre Jacobo Cromberger, el famoso impresor sevillano quien a su vez había continuado la empresa de Stanislao Polono, el impresor de la Comedia de Sevilla, i501. Durante los años en que la famosa imprenta sevillana estuvo al mando de Jacobo Cromberger solo, es decir entre $1504 \mathrm{y}$ 1525, salieron de ese taller cuanto menos tres ediciones de la Tragicomedia, entre las que se contaba la que lleva por título Libro de Calixto y Melibea y de la puta vieja Celestina. Padre e hijo juntos imprimieron por lo menos dos ediciones más en 1525 y 1528 respectivamente, y en 1535 Juan imprimió otra más de la que afortunadamente se nos ha conservado un ejemplar recientemente descubierto. $74 \mathrm{Si}$ bien podriamos inclinarnos a pensar que los "262 calistos" serian ejemplares de la edición de Sevilla, 1518-1520 con su título original, la verdad es que ejemplares de cualquiera de estas ediciones, de una o de todas ellas podrian naberse 
contado entre esos "262 Calistos" Y esas "63 Celestinas" que se habian acumulado en la casa de ios impresores a io largo de los años. Además ino nabria quizás entre todos ellos algún que otro ejemplar de ediciones impresas por otros impresores?

En 1541, después de morir Fernando de Rojas, su mujer Leonor Aluares declaró en el inventario de bienes que les nabía legado diciendo que entre los libros nubo "Yten el libro de Calisto". 15

En 1559 Juan Timoneda, al tratar del estilo cómico en el que se pintan vicios $v$ virtudes, da como ejemplo la obra de Fernando de Rojas: "bien lo supo el que compuso los amores de Calisto $Y$ Melibea" 76 todavía en 1615 Suárez de Figueroa observa que "en la Tragedia de Calixto, Celestina inflama con tales cosas a Melibea."

Con todo, como ya observó Keith Whinnom, 78 muy pronto la obra empezó a llamarse Celestina. Basta consultar los trabajos de F. Rodríguez Marín, 79 de Irving Leonard, 80 de Maria Rosa Lida de Malkiel $81 \mathrm{y}$, más recientemente, los de Pierre Heugas $\mathrm{v}$ de Maxime Chevalier 83 que citan comentarios de muchos críticos $y$ lectores para comprobarlo. Ya en 1531 Francisco de Osuna escribe de "quienes leen a Celestina o a otros semejantes, "84 y volverá a Ilamar ía obra así en 1536.85 Entre 1535 y 1536 Juan de Valdés, estando en Nápoles, al escribir su Diálogo de la iengua, ía Ilama Celestina en cres ocasiones. ${ }^{6}$. Para Alejo de Venegas será scelestina en $1540^{87}$ y en 1541 Blasco de Garay se queja "de los que suelen leer sino a Celestina o cosas semejantes."88 Asi la llamaban hacia mediados del siglo XVI Fray Luis de Alarcón 89 y Jerónimo Zurita.90 En la Farsa salmantina de Bartolomé Palau, publicada en 1552, un escolar se queja de su pobreza y de su miserable biblioteca:

$$
\begin{aligned}
& \text { "... iLibros?; } \\
& \text { pues vos lo veed:" } \\
& \text { vna Celestina vieja } \\
& \text { v vn Phelipo de ayer."91 }
\end{aligned}
$$

En 1570 Martín de Azpilcueta escribe de "un libro que Ilaman Celestina" 92 y Simón Borgoñón, en ia dedicatoria de su edición--que Ileva por título Tragicomedia de Calisto $\mathrm{V}$ Melibea--cuenta haber conocido a vn "docto religioso q(ue)" le nabía dicho que "no absolveria de buena gana aquie( $n$ ) en Celestina leer acostu(m)brasse." 93 unos quince años más tarde, Andrés Rey de Artieda citará a Celestina como ejemplo94 mientras que Fray Juan de Pineda, en 1589, tratará de la "leccion de Celestina."95 Hasta en el Nuevo Mundo, en un sinodo en Tucumán, allá por 1597, Celestina se halla entre 1056 "libros torpes" que deben ser recogidos V quemados.96 Y si antes se ilamaba iibro de Calisto en algunos documentos legales, en la segunda mitad del siglo 
XVI, en una sentencia contra Rafaela Pérez, acusada de hechicera en 1566, leemos: "... dixo que diziendole cierta persona que en el Iibro de Celestina..."97 En 1584, en la "Probanza de hidalguia" del licenciado Hernando de Rojas, nieto del autor de nuestra Tragicomedia., Antonio de Salaçar y Blas Rodríguez, dos testigos, informando del abuelo, afirman que de él se decía que "hauia hecho" el libro llamado Celestina" 98 y Hernando de Benabides, otro testigo más, también informa del abuelo "que dicen que fue el que compuso el libro decelestina." 99

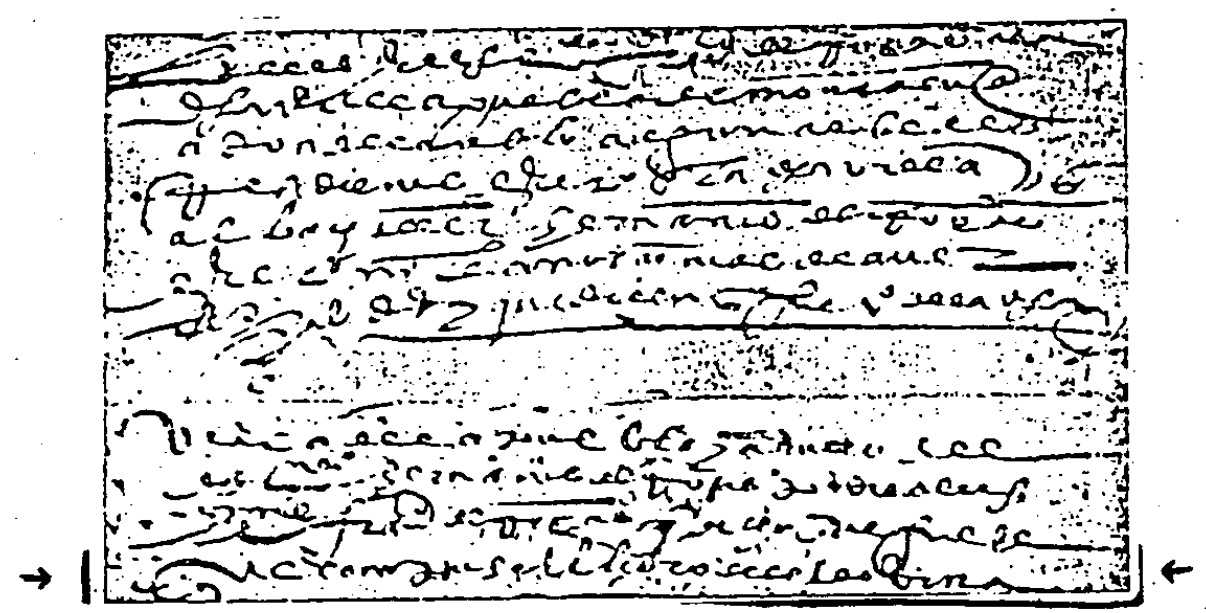

36. Facsímil del trozo final de la p. 16 y principio de $1 \mathrm{a}$ p. 17 de la probanza de hidalguía de sangre del licenciado Hernando de Roxas [1584]

En el Arbol genealógico de la familia de los Franco, cuyo contenido publicó Gilman, 100 el bachiller Rojas queda identificado como el "que compuso a Celestina la vieja," título con el que rambién se menciona la obra repetidas veces en el "expediente de limpieza" de don J. F. Palavesín $Y$ Rojas de i616.i01 Con el tituio de Celestina ia vieja, como con el de Primera Celestina o Celestina primera, se aistinguia la obra original de Rojas de sus imitaciones.

En los inventarios de bienes también muy pronto se ilama al libro Celestina. En Barcelona, en 1537-38, Erancesc Terre tiene "una Celestina"102 y en otro inventario del año siguiente, también en Barcelona, se mencionan "dos Salestinas."103 En el de Cristóbal de la quadra de Valladolid, en 1559; hallamos "vna celestina".104 En 1576 un mercader de la ciudad de México, en un documento que publicó Irving Leonard, promete pagar por "6 Selestinas, papelones a 3 reales" $\underline{v}$ por "12 Selestinas, Anveres, tablas a 3 reales", 105 v nay que recordar que para esas fechas las ediciones publicadas en Amberes aun no llevaban el título de Celestina en las portadas. En 1583, en una escritura redactada en Lima, se mencionan " 12 celestinas de las mas 
chicas con flores de oro la meitad [sic] v la otra mitad en pergamino."106 En el inventario de un profesor de Prima de Filosofia de la Universidad de valladolid, en i584; se menciona una "Celestina, 160"107 v también en el inventario de la biblioteca del Inca Garcilaso, firmado en Córdoba en 1616, figura una Celestina. 108

A principios del siglo XVII Francisco López de Ubeda escribe del "tono del libro de Celestina"lo9 y Lope $y$ Cervantes llaman a la obra Celestina. 110

Todo ello se debe indudablemente al hecho de que el público español también percibiera al personaje de la alcahueta creado por Fernando de Rojas como el más importante de la obra, pues si bien hay comentarios sobre ios amantes $Y$ sobre algún que otro personaje, exceden en cantidad los que se refieren a Celestina. Como señaló Chevalier, Celestina como personaje fascinaba a los españoles provocando en ellos diversas reacciones. 111 Llegó a ser personaje popular que aparece en obras burlescas, que entra en el mundo del Romancero, que forma parte del refranero, del folklore estudiantil salmantino y que, como señaló Rodríguez Marín, aparece hasta en un desfile, según relata Sebastián Horozco allá por 1555: "... iba çelestina

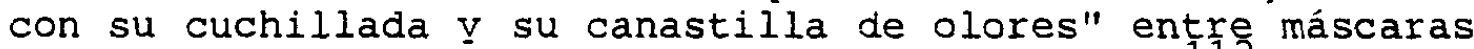
de moros, judíos, cardenales, monjas y viudas.112. Era el personaje que más nabía impresionado a los lectores $y$, por ello, Ios amantes tuvieron que cederle su lugar en el titulo.

Como señaló Whinnom, durante el siglo XVI, cuando se llamaba al Iibro Celestina, aparecia sin el artículo.113 En una sola ocasion hemos hallado el nombre del libro precedido por el articulo usado en el siglo XVI, $\underline{v}$ en esa ocasión, bien puede no formar parte del titulo: en el testamento de Juan López Enríquez de Calatayud de 1570, donde se menciona "Otro libro chequito que es la Celestina."114 Aun en el siglo XVII, la mayoría de los que mencionan la obra, la llaman Celestina. Unos pocos, como Salas Barbadillo, 115 Gracián 116 y, en una ocasión, Quevedol17 le anteponen el articulo, pero bien pueden haber anticipado la regla del español moderno: "cuando una obra tiene por titulo un personaje, se dice el otelo," es decir, el articulo no forma parte del titulo, como señaló Whinnom. 118 pero si esto es asi, nos preguntamos ipor qué don León Amarita, al publicar ia primera edición moderna después de un intervalo de casi dos siglos que pasaron sin que se publicara una sola edición españolás prepara su edición con la siguiente portada en 1822?:119 
37. Portada de la primera edición moderna impresa por León Amarita en Madrid 1822

(Colección privada de Joseph. Snow)

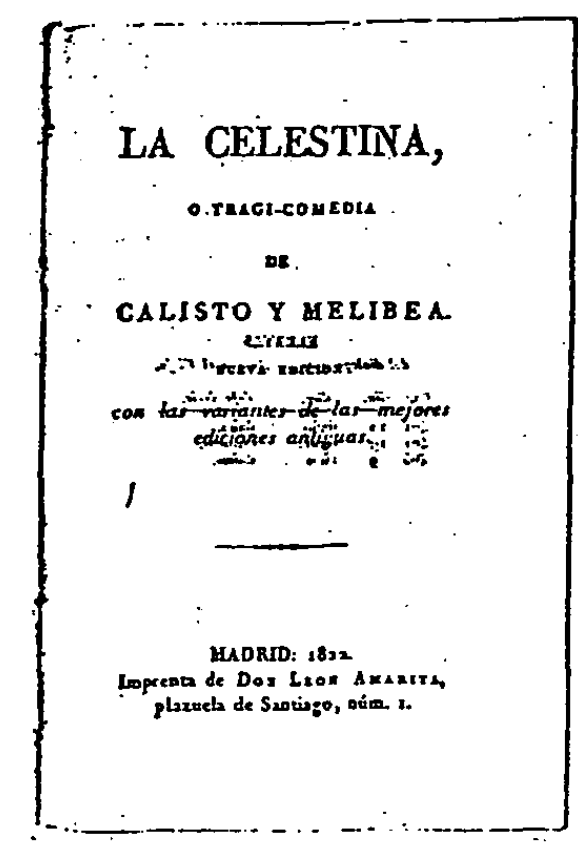

¿Habrá contribuído a ello la costumbre de que se usara a veces el articulo ante nombres de gente humilde en la lengua familiar $y$ coloquial? ¿o el que se emplee el artículo con nombres propios de mujeres célebres como, por ejemplo, en el caso de la Raquel? ¿O el hecho de que entre todas las Celestinas que se escribieron, la de Fernando de Rojas era ia que se destacaba más? ¿o se deberá la costumbre de incluir el articulo en el título a una influencia francesa? posiblemente se debe a una conjunción de varias razones.

Eernando de Rojas, despues de ampliar ia comedia, la Ilamo Tragicomedia de Calisto $y$ ielibea. Para Ios traductores italianos $y$ para el vulgo español el nombre muy pronto llegó a ser Celestina. Los traductores franceses, a partir de 1578, la titularon La Celestine, $\mathrm{V}$ si bien Celestina puede parecernos preferible, ha sido La Celestina el título por el que optaron a partir de 1822 los impresores del texto español de la Tragicomedia en el mundo nispánico, 120 titulo que se ha arraigado $v$ por el que se conoce hoy la famosa obra de Fernando de Rojas.

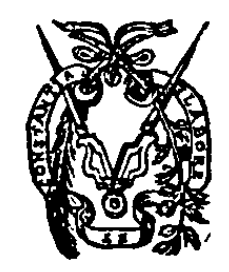


NOTAS

isee Keith Whinnom, "La Celestina', 'The Celestina', and L2 Interference in L1," Celestinesca, 4:2 (1980) 19-21.

2 Según Fernando de Rojas nos informa en el "prologo" a la obra en veintiún actos, estos argumentos añadidos le parecian superfluos: "... q(ue) avn los imp(re)ssores ha(n) dado sus pu(n)turas: poniendo rubricas: 0 sumarios al pri(n)cipio de cada acto narra(n)do $e(n)$ breue 10 q(ue) dentro contenia, vna cosa bie(n) escusada, segu(n) lo q(ue) los antiguos escritores vsaron..." (Toledo, 1510-1514). Fernando de Rojas parece referirse aqui a lo expresado por Terencio en el prólogo del Andria.

${ }^{3}$ La edición de Burgos que se supone impresa en 1499 , cuyo único ejemplar se conserva en The Hispanic Society of America, como es sabido, carece de portada, de todo el material preliminar $\mathrm{y}$ del que sigue al acto XVI en las otras dos ediciones de la Comedia.

4 También se anuncia en la primera página de la edición de Burgos, ¿1499?

${ }^{5}$ Creemos que aquí no se refiere a la interpretación del personaje de Calisto, sino al nombre que solia darse a la obra, pues como se verá más adelante, en varias ocasiones se menciona en documentos legales al autor que "compuso a Calisto"; se enumera a la obra como "Calisto" o se habla del "Libro de Calisto." Aún hoy en dia, en el General Catalogue of The British Museum, ia Tragicomedia se halla catalogada bajo el nombre "Calisto."

6impresa por "Eucharium Silber alias Franck." Consta de veintiún actos. Se titula: TRAGICOMEDIA DI.CALI // STO E MELIBEA NOVAMEN // TE TRADVCTA DE // SPAGNOLO IN // ITALIANO $1 /$ IDIOMA. Para la descripción y localización de ejemplares de esta edición ver Emma Scoles, "La prima traduzione italiana della 'Celestina': repertorio bibliografico." Studi di Letteratura Spagnola, Roma, 1964, p. 213.

7 printing in spain, 1501-1520, Cambridge, 1966, en particular "Appendix B"--The Early Editions of 'Celestina'." pp. 141-156.

${ }^{8}$ Nicolás Gazini de Piemonte y Juan de Villaquirán. Ver Norton, op. cit., pp. 154-155.

${ }^{9}$ Según nemos podido constatar, aparte de la de Toledo, 1510-1514 $\mathrm{V}$ de la de Sevilla de hacia i511 ya mencionadas, de las impresas en España que se han conservado, solamente 


\section{CELESTINESCA}

las ediciones de Barcelona, 1531, de Medina del Campo, 1566, de Madrid, 1569 v de Toledo, 1573 mantienen en el subtítulo "en la qual se contiene." En todas las demás con subtítulo en la portada leemos "en la qual se contienen."

iOEl ejemplar único conservado de esta edición se halla en The British Library, Londres (Signatura C. 64. d. 4).

ilel ünico ejemplar que se conserva de esta edición se encuentra en The British Library, Londres (Signatura C. 63. i. 15$)$.

12El ejemplar único conservado de esta edición se encuentra en The British Library, Londres (Signatura G. 102331 .

i3 De esta edición se han conservado dos ejemplares: 1) el de The Hispanic Society of America en cuya tapa interior leemos "2.8.56 Gift of A. M. Huntington," nota que explica por qué no la naya incluído clara L. Penney en su libro The Book Called Celestina, New York, 1954; 2$)$ el que îe localizado recientemente por Ivana Gallo y Emma Scoles en la Biblioteca Nacional, Madrid. (Signatura $R$ 30275). Ver "Edizioni antiche delia 'Celestina' sconosciute 0 non localizzate dalla tradizione bibliografica," Cultura Neolatina, XLIII (1983), p. 8 .

14 Ina excepción la constituye la edición de Salamanca, 1543 impresa en casa de Juan de Junta de cuya portada ofrece una reproducción facsimilar reducida Clara $\bar{L}$. Penney, op. cit., p. 105. Según observa Griffin en su articulo "Four Rare Editions of 'La Celestina'," The Modern Language Review, July 1980, Vol. 75, p. 563, y como ya señaló Givanel Más en la descripción del ejemplar, esta edición presenta la peculiaridad de tener el "Auto de Traso" al final del libro, después de las octavas finales de Proaza y no como acto diecinueve, como es el caso en las otras ediciones que lo incorporan en.el texto.

15Este es el caso de las ediciones de Burgos, 1531; Sevilla, 1535; Burgos, 1536; Çaragoça, 1545, impresa por G. Coci; Sevilla, 1550 donde la información aparece antes de ias octavas Iinales; Çaragoça, 1555; Cuenca, 1561; Y valladolid, 1561-62.

${ }^{16}$ Los dos ejemplares conservados de esta edición se hallan en 1) The Hispanic Society of America, New York; y 2) la Biblioteca Nacional, Madrid (Signatura R 4423).

\footnotetext{
17 Penney, op. cit., p. 18.

18 Articulos citados en notas 13 y 14.
} 
${ }^{19} \mathrm{Se}$ trata de: 1) la impresa en valladolid, posiblemente entre 1526 y 1540, acaso por Nicolas Thierry, como sugiere Griffin, cuyo único ejemplar conservado se encuentra en la Saltykov-shchedrin state Public Library; Leningrado (Signatura 6.20.4.24). Tras título y subtitulo ieemos: "... en siruie(n)tes y Alcahuetas, co(n)el trata--// do de Centurio:y el auto de Traso"; 2) la de Estella, 1557 impresa por Adrian de Anvers, recientemente localizada por Gallo y Scoles que se encuentra en la . Bayerische Staatsbibliothek, Monaco (Signatura B.L.hisp. p. 53); 3 ) la otra de Estella, 1560 también de Adrian de Anvers, que se halla en la Biblioteka Jagiellonska, Cracovia (Signatura Cim. i281). En las portadas de las dos de Estella se anuncia: "Ua aqui añadido el Tratado // de Centurio, y el aucto de Traso." Ver Griffin, op. cit., pp. 563-570. Ver el trabajo de Gallo y Scoles, op. cit., p. 5.

20Impresa en Barcelona. El ejemplar se halla en The Hispanic Society of America. Ver Penney, op. cit., p. 58.

21 penney incluyó en p. 107 de su libro la reproducción facsimilar reducida de la portada de esta edición tomada del Manual de $F$. Vindel. El ejemplar único conservado de esta edición se halla en ia Biblioteca Nacional, Madrid (Signatura $R$ 31686) donde fue localizado recientemente por Gallo y Scoles. Op. cit., p. 11.

22 Tal es el caso, por ejemplo, de ia de Estella, 1560, impresa por Adrian de Anvers, a pesar de que en el colofón se lea: "con expresso permisso // del Real consejo de Naua// rra;" de ia de valladolid, 1561-62, de Francisco Fernandez de Cordoua, no obstante se anuncie en la portada: "con licencia delos.// señores del consejo de su Magestad Impressa:" de la de Alcalá, 1563, cuyos impresores, Francisco Cormellas y Pedro de Robles, anuncian en la portada: "...con iicencia impressa;" 10 mismo lo observamos en la de Medina del Campo, 1563, por Francisco del Campo; en ia portada de la de Sevilla, 1575, de Alonso Picardo, a pesar de que leamos: "con licencia de los señores // del Consejo Real," vemos que carece del texto del permiso; en la portada de la de Valencia, 1575, de Juan Navarro se nos informa "Uista, y examinada, en Valencia," pero no contiene el texto, como también ocurre con la de sevilla, 1582, de Alonso de la Barrera, no obstante se anuncie en la portada: "Con licencia del Consejo Real."

23 El ejemplar único que se conserva de esta edición fue localizado hace poco por clive Griffin $Y$ se halla en la Jagielion Library, Cracovia (Signatura Starodruki Cim 5689), op. cit., p. 571 .

${ }^{24} \mathrm{El}$ ejemplar unico de esta edición se conserva en la Biblioteca del Palacio de Madrid (Signatura I.C.266). También se le ilama "Celestina primera" en la licencia 
fechada en Madrid, a 20 de marzo de 1569 obtenida por Mathias Gast para su edición publicada en Salamanca, 1570.

$25_{E l}$ ejemplar único conservado de esta edición se halla en The Hispanic Society of America. Ver Penney, op. cit., pp. $60-62$.

26 También se le ilama "primera Celestina" en la Iicencia obtenida en Madrid el 18 de septiembre de 1569 por Francisco de Guzmán para su edición impresa en Toledo, 1573, como también en la tasa fechada en Madrid el 20 de julio del mismo año. Igualmente en la edición de Pierres Cosin, impresa en Madrid en 1569, cuyo ünico ejemplar conservado se halla en la Fales Library, parte de la Elmer Holmes Bobst Library de New York University (PQ 6426 A1 1569) en el fol. $A-V$ se nos dice que "fue tassado el libro intitulado celestina primera..." En el fol. A2r se menciona al "libro que se intitula primera Celestina..." $y$ en la "Provision Real" en el fol. A2v se vuelve a mencionar a Celestina primera.

27 Como puede verse en la licencia otorgada en Madrid el 2 de diciembre de 1574 a Juan de Lequerica para la edición de Alcalá, 1575; en la licencia concedida a Alvaro Vrsino de Portonariis del 20 de febrero de 1573 para su edición que apareció en Salamanca, 1575; en la licencia dada en Madrid, en diciembre de 1574 que contiene la edición de Salamanca, 1590 (in fine:) 1591, impresa por Iuan y Andres Renaut para Claudio Curlet; en la suma de licencia del 26 de mayo de 1631, en la aprobación del 7 de noviembre de 1631 v en la suma de tasa del 10 de noviembre del mismo año concedidas a la Viuda de Alo(n)so Martin cuya edición se imprimió a costa de Domingo Gonçalez en Madrid, 1632.

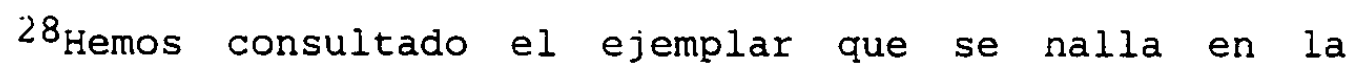
Biblioteca Nacional, Madrid (Signatura U 4005). Otro ejemplar de esta edición se halla en The Hispanic Society of Àmerica.

${ }^{29} \mathrm{La}$ licencia fue expedida en Madrid, el il de agosto de 1581. Hemos consultado el ejemplar de esta edición que se encuentra en la Biblioteca Nacional, Madrid (Signatura 7491). Otro ejemplar se halla en The Joseph Regenstein Iibrary en la Universidad de Chicago.

${ }^{30}$ Como puede verse en la licencia expedida en Madrid el 16 de febrero de 1586 para la edición de Juan Gracián publicada en Alcalá el mismo año; en la licencia otorgada en Madrid el 10 de abril de 1590 a Hernán Ramirez para su edición que apareció en Alcalá de Henares en 1591; en la iicencia expedida en Madrid el 27 de enero de 1573 que se incluye en la edición de Felipe Roberto publicada en Tarragona en 1595; $\underline{y}$ en la licencia del 1 de febrero de i616, en ia aprobación del 22 de noviembre de 1618 y en ia 
tasa del 28 de noviembre del mismo año incluídas en ia edición impresa por Iuan de la Cuesta a costa de Miguel Martínez en Madrid en 1619.

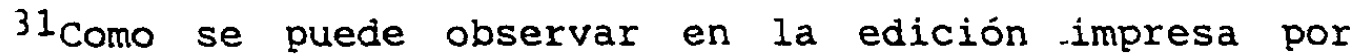
Andres $\mathrm{Sa}(\mathrm{n})$ ches a costa de Miguel Martinez impresa en Madrid en 1601. Ejemplares de esta edición se hallan en la Biblioteca Nacional, Madrid (Signatura $R$ 3750); en The Hispanic Society of America; en la Hebrew Union College Library, Cincinnati (Signatura RBR E/R); $\underline{V}$ en la Joseph Regenstein Library de la Universidad de Chicago.

32 Ejemplares de esta edición se hallan en la Biblioteca Nacional, Madrid (Signatura R 11954); en la Oesterreichische Nationalbibliothek, Viena (Signatura $38 \mathrm{~L} \mathrm{96);} \mathrm{Y} \mathrm{en} \mathrm{The}$ Hispanic Society of America.

33 Asi también se encuentran encabezadas las páginas de la edición de Barcelona, 1561, impresa por Claudi Bornat, y las de un ejemplar sin Fecha que se nalla en la Biblioteca Nacional, Madrid (Signatura $R$ 3340). Desafortunadamente se trata de un ejemplar mutilado que carece de todo el material preliminar como también del que se encuentra por io general al final de las ediciones.

34 ver Penney, op. cit., pp. 79-80. Además de los ejemplares de esta edición citados en el libro de Penney, existen otros en The British Library (Signatura 1072. C. 19); en la colección de J. Sedó Peris-Mencheta, Barcelona; Y en The Memorial Library, University of Wisconsin, Madison. El mismo titulo vuelve a aparecer en la portada de la edición de Carlos Labayen impresa en Pamplona en 1633.

35 ver nota 6 .

36 ver scoles, op. cit., p. 215. Además de los ejemplares de esta eaición incluidos en el repertorio de Scoles, hemos localizado el de The Houghton Library, Harvard University, Cambridge, Massachusetts (Signatura *SC5 R6382C Ei506ob).

37Ver scoles, op. cit., pp. 215-216. Otro ejemplar se halla en The Houghton Library, Harvard University, Cambridge, MA, cuya portada y colofón reproducimos.

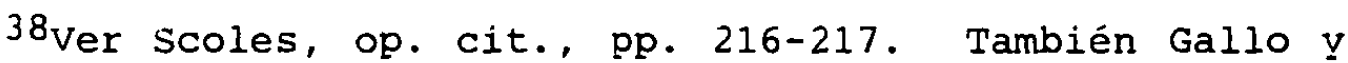
Scoles, op. cit.. p. 12. Hemos encontrado otro ejemplar en The Houghton Library, Harvard University, Cambridge, MA (Signatura *SC5 R6382C Ei 5060d).

${ }^{39}$ ver scoles, op. cit., pp. 217-218. Gallo y scoles hallaron varios ejemplares más. ver op. cit., p. I3. Además hemos hallado otro ejemplar en The Folger Shakespeare Library, Washington, D.C. (Signatura PQ 6427 I8 1519 Cage). 


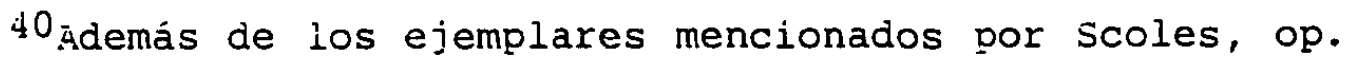
cit., pp. 218-219, $y$ del de la Biblioteca Nacional, Madrid (Signatura R 1434), otros ires ejemplares se hallan en las siguientes bibliotecas en los Estados Unidos: 1) en Haverford College Library, Haverford, Pennsylvania (Signatura $\mathrm{PQ} 6427$. I8 1519); 2 ) en The Library of the University of Iowa, Iowa City (Signatura XPQ 6427 I8 1519); en Wellesley College Iibrary, Wellesiey, Massachusetts isignatura Plimpton 187).

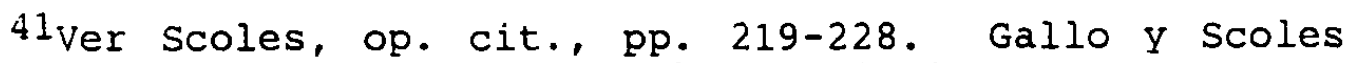
hallaron numerosos ejemplares más en bibliotecas europeas, op. cit. pp. 12-16. Además hemos localizado ejemplares de varias ediciones de traducciones italianas en algunas bibliotecas en Ios Estados unidos. Próximamente publicaremos el elenco de todas las ediciones y traducciones italianas $v$ francesas que se pueden consultar en este país. en Puerto Rico y en el Canadá.

42 Celestine. A Critical Edition of the First French Transiation (1527) of the Spanish Classic La Celestina. Detroit, 1963, pp. 6-7. Para los titulos y ejemplares conservados de las ediciones de traducciones francesas ver Appendix I, pp. 213-218.

$$
43 \text { op. cit., p. } 17 \text {. }
$$

44 Ver Fernando de Rojas, La Celestine in the French translation of 1578 Dy Jacques de Lavardin, a critical edition with introduction and notes by Denis L. Drysdall, Tamesis Books Limited, London, 1974.

45 ver Brault, op. cit., pp. 217-218.

46"The Lowlands Printings of Celestina (1539-1601)," Celestinesca, 5:1 (1981) p. 8 .

47 Afortunadamente de esta edición de la que parecía que no se nabia conservado ningún ejemplar, Gallo y Scoles localizaron cuatro ejemplares en bibliotecas europeas. Op. cit., p. 10 .

48 Aparte de los ejemplares de la Biblioteca Nacional, Madrid (Signaturas $R 7836$ y U 7810 ) hay un ejemplar en lá Biblioteca da Ajuda, Lisboa (Signatura 77A-I-38) y otro más en The Memorial Library, University of Wisconsin. (Signatura Rare Book Coliection 715363). El ejemplar que perteneció a J. Peeters-Fontainas fue adquirido por Moorthamers, Bruselas.

49 Ver Eugenio Krapf, "Ediciones de la 'Celestina'..." en La Celestina... conforme a la edición de Valencia de 1514, reprodúcción de la de Salamanca de 1500, con una introducción del doctor d. M. Menéndez y Pelayo, Vigo, 1900 , 
Tomo II, j5) p. KLV. Desafortunadamente de esta edición no se ha localizado ningún ejemplar hasta la fecha.

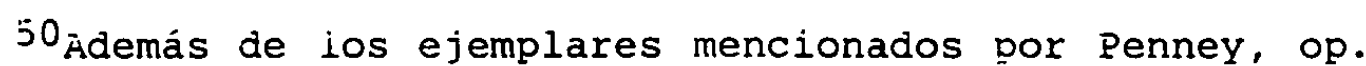
cit. pp. 68-70, hemos localizado varios ejemplares en bibliotecas estadounidenses que incluiremos en el elenco por publicar. El ejemplar que perteneció a J. Peeters-Fontainas se halla ahora en la Biblioteca de la Universidad de Leiden.

$51_{\text {Ver }}$ Penney, op. cit., p. 73 donde menciona variantes de estas ediciones. De cuatro ejemplares que pertenecieron a J. Peeters-Fontainas, dos pasaron a la Biblioteca de la Universidad de Leiden, una fue adquirida por The Hispanic Society of America, New York y la otra fue comprada por Angel Perela, Tudela del Duero, Valladolid, España. En nuestro elenco por publicar incluiremos la lista de los ejemplares de esta edición que pueden consultarse en algunas bibliotecas en los Estados Unidos.

52 Ver Krapf, op. cit., 65) p. XLIX.

53 Citado en ia introducción a ia edición preparada por Guadalupe Martinez Lacalle, CELESTINE or the TRAGICK COMEDIE of CALISTO and MELIBEA, Translated by James Mabbe, Tamesis, London, 1972, p. 3 .

54 Salvo "the tragical Comedie of Calistus," 1580. Ver Martinez Lacalle, op. cit., pp. 5-6.

55 Ver Martinez Lacalle, op. cit., p. 34.

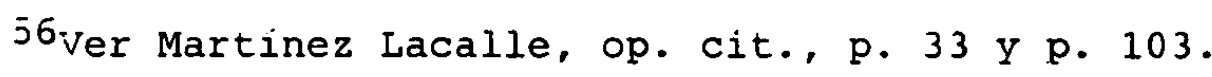

57Ver Martinez Lacalle, op. cit., pp. 107-108.

58 Gracias a la edición preparada por Kathleen $V$. Kish $y$ Ursula Ritzenhoff, Die Celestina-Ubersetzungen von Christof Wirsung, Georg olms Verlag, Hildesheim--Zurich--New York, 1984, ias dos traducciones de Christof Wirsung son ahora de fácil acceso.

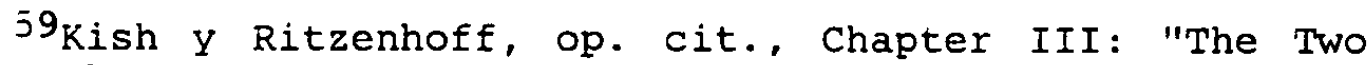
Sixteenth-Century German Celestina Translations," p. $20 \mathrm{Y}$ nota 10 en pp. 97-98.

60 Ain Hipsche Tragedia, editado por Kish y Ritzenhoff, op. cit., Fol. A ij (r).

${ }^{61}$ Podria traducirse: "Un librito bien ameno $y$ a la vez una triste comedia (por tanto Ilamada Tragicocomedia por los [escritores] latinos) de la cual el lector colige un informe útil sobre el daño y peligro del amor carnal, la alevosía de los criados, las mañas de las mujeres lascivas, la astucia y codicia de los alcahuetes, y en la que, cual en un espejo, 


\section{CELESTINESCA}

también puede ver $y$ aprender diversas costumbres $y$ cualidades de los seres humanos.

$$
\text { 620p. Cit., Folios Aij r., Aiij v., Aiiij r., Avi v., }
$$

Avij r. Y Aviij $r$.

$$
\begin{aligned}
& \text { 63op. cit., Folio Aij v. } \\
& 64 \text { op. cit., Folios Ailj r. Y Aviij. } \\
& 650 p \text {. cit., Folios Aiij v. Y Aiij r. } \\
& 66 \text { op. cit., Folio Aiiij v. } \\
& 67 \text { Op. cit., Folio Av v. } \\
& 68 \text { op. cit., Folio Avi v. } \\
& 69 \text { op. cit., Folio Avii v. }
\end{aligned}
$$

70 "Noticias biográficas de Fernando de Rojas autor de La Celestina y del impresor Juan de Lucena," Revista de archivos, bibliotecas y museos, año VI (Abril y Mayo, 1902), pp. 247 y 263. Quizás sea oportuno mencionar aquí el titulo que lleva el poema compuesto para la perdida traducción hebrea de J. Sarfati de ia obra de Rojas. Según Shalom Carmy, traducido del hebreo al inglés tendríamos: "Poem Composed by the poet on translating (or copying) the Composition of Melibea and Calisto." (Obsérvese la inversión del orden acostumbrado de ios nombres de los amantes). Si bien ignoramos ia iecha exacta de ia traducción, tiene que naber sido anterior a 1527, año en que Sarfati falleció. Sylvia Simpson Genske, 'La Celestina' in Translation Before 1530, PhD dissertation, New York University, 1978, p. 41.

$71_{\text {Citado por Irving Leonard, Los libros del }}$ conquistador, segunda edición en español, México, 1979, D. 82. Hemos consultado el manuscrito R-10873 en la Bibiloteca Nacional, Madrid.

72 Aviso de Privados y Doctrina de Cortesanos impreso en Valladolid por Juan Villaquirán, 1539, hoja $7 a$ sin foliar. Citado por Menéndez Pelayo en origenes de la novela, Santander, 1943, Vol. III, p. 389, nota 1 .

$73 \mathrm{D}$. José Gestoso $\underline{y}$ Pérez, Noticias Inéditas de Impresores Sevillanos, Sevilla, 1924, p. 90 y p. 91.

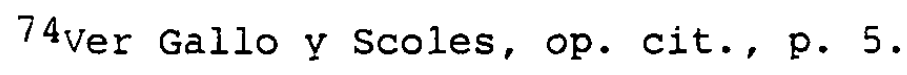

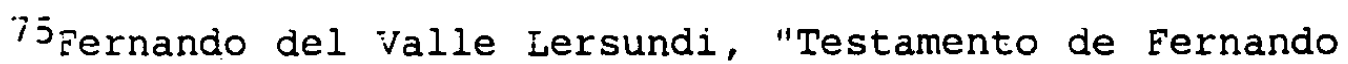
de Rojas, autor de 'La Celestina'." Revista de filologia española, 16 (1929), 382 . 
${ }^{76}$ Citado por Maria Rosa iida de Malkiel, La originalidad artistica de 'La Celestina', Buenos Aires, 1962 , p. 55 .

77 Citado por M. Herrero-Garcia, Estimaciones Literarias deI Siglo XVII, Madrid, 1930, p. 42.

78 op. cit.. p. 20 .

79"La Celestina." en su edición de El ingenioso hidalgo don quijote de la Mancha, tomo IX, Madrid, 1949, pp. 69-75.

80 op. cit., pp. $81,82,107,335,339,409$.

81 op. cit., pp. 11-26, 50-55, 294-300.

82 "La célestinesque et son histoire," 'La Celestine' et sa descendance directe. Institut d'Etudes Ibériques et Ibéro-Américaines de l'Université de Bordeaux, 1973, pp. 1347 .

83" Ia Celestina' según sus iectores," Lectura y iectores en la España de ios siglos XVI y XVII, Madrid, 1976, pp. 138-166.

$84 \mathrm{En}$ su Norte de Los estados, تolio 85 , citado por Rodriguez Marín, op. cit., tomo IX, p. 70.

85 Ibid., p. 72.

86Edición $Y$ notas por José $F$. Montesinos, Cläsicos Castellanos, Madrid, 1964, pp. 182 y 183.

87 Ver Chevalier, op. cit., p. 156.

${ }^{88}$ Citado por Heugas, op. cit., p. 16 , nota 7 .

39 Citado por Lida de Malkiei, op. cit., p. 294, nota 12.

90 Citado por Menéndez Pelayo, op. Cit., III, p. 390.

9 lcitado por Rodríguez Marín, op. cit., tomo IX, p. 71. 92 Ibid., p. 72 .

93Edición Mathias Gast, British iquseum (Signatura i1725. a. 8.) fol A3r.

${ }^{94}$ Citado por Rodriguez Marín, op. cit., tomo IX, p. 70 .

95 Diálogos familiares de la agricultura cristiana, B.A.E., 169, p. 49ab, citado por Chevalier, op. cit., p. 158 . 
96. Vhevalier, op. cit., p. 159.

97 Archivo Histórico Nacional, Inquisición de Toledo, Iegajo 27 de causas, núm. 10. Citado por Rodríguez Marín, op. cit., p. 75 .

98 Ver Stephen Gilman, The Spain of Fernando de Rojas, princeton University Press, 1972, Appendix III: The Probanza de hidalguia of Licentiate Fernando de Rojas, pp. 509 Y 512.

99 Ver Fernando dei valle Lersundi, "Documentos referentes a Fernando de Rojas," Revista de filología española, XII $(1925)$, pp. 394 y 395, en la que se reproduce el facsímil del que incluimos una reproducción.

100. Ver Gilman, op. cit., Appendix II, p. 502.

${ }^{101}$ Narciso de Esténaga, "Sobre el Bachiller Hernando de Rojas y otros varones toledanos del mismo apellido," Boletín de la Real Academia de Bellas Artes y Ciencias Históricas de Toledo, (1923), p. 81 .

102José M.a Madurell Marimón y Jorge Rubió Balaguer, Documentos para la nistoria de la imprenta $v$ libreria en Barcelona (1474-1553), Barcelona, 1955, Doc. núm. 439 bis, p. 759. Citado por Chevalier, op. cit., p. 140.

103 Madurell Marimón y Rubió Balaguer, op. cit., Doc. núm. 413, p. 724 .

104 Legajo 55, fol. $1234 \mathrm{v}$ que hemos consultado en el Archivo Histórico Provincial de Valladolid.

105ver Leonard, op. cit., Apéndice: Documento II, "Pagaré de Alfonso Losa, Mercader de libros," p. 335.

106 Ibid, Apéndice: Documento III, "Escritura de Erancisco de la Hoz a Juan Jiménez del Río," p. 339.

107 Legajo 571, fol. $1316 \mathrm{v}$ que hemos consultado en el Àrchivo Histórico Provincial de valladolid.

108.José Durand, "La biblioteca del Inca Garcilaso de la Vega," Nueva Revista de Filología Hispánica, (1948), p. 253.

i09ver Chevalier, op. cit.; p. 159.

110Ver Herrero Garcia, op. cit., re.: Lope, pp. 11, 26, $36 \mathrm{y} 58$. Cervantes, en los conocidos versos de cabo roto de la composición "Del Donoso, poeta entreverado, a Sancho Panza Y Rocinante," Don Quijote de la Mancha, edición de Martín de Riquer, Barcelona, 1968, p. 32.

illop. cit., especialmente pp. 44-166. 
112 Rodriguez Marín, en su edición de Don Quijote, tomo IX, Madrid, 1949, p. 71.

113 op. cit., Celestinesca, 4:2 (1980), pp. 19-20.

${ }^{114}$ Narciso Alonso Cortés, "El traductor de Ludovico. Dolce," Miscelánea vallisoletana, tomo I, 1955, p. 633 .

115 Citado por Lida de Malkiel, op. cit., p. 57.

116 Citado por Menéndez Pelayo, op. cit., III, p. 406, nota 2 .

117 En el prólogo a la Eufrosina traducida al castellano por Fernando de Ballesteros y Saavedra. Citado en Menéndez Pelayo, op. cit., III, p. 456. En su España defendida menciona la obra sin el articulo. ver Lida de MalkieI, op. cit., p. 298 .

1180p. cit., Celestinesca, 4:2 (1980), p. 20.

119 Don León Amarita concientemente preparó la portada con el título LA CELESTINA, pero queriendo ser fiel al texto original, incluyó una segunda portada interior con el título de CELESTINA.

120 Cuando hacia mediados del siglo XIX se incluye la Tragicomedia en el volumen 3 de la Biblioteca de autores españoles, en el tomo, dedicado a "Novelistas anteriores a Cervantes", la obra carece de portada, y si bien en página 1 el título aparece como. CELESTINA antes del material preliminar, en página 5, antes del argumento del acto primero, aparece el título LA CELESTINA, titulo que encabeza ios folios rectos a io largo de toda ia obra y que se incluye en igual forma en el indice del tomo.

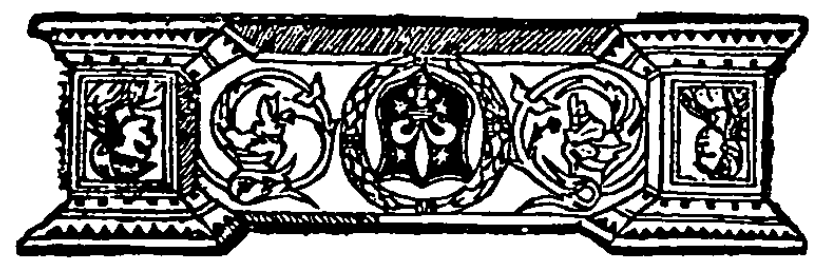


Medieval Studies/Spanish Literature

\section{La Celestina}

Tragicomedia de Calisto y Melibea

Fernando de Rojas

Volume I: Introducción

Volume II: Edicion Crítica
With the publication of Miguel Marciales's critical edition of Celestina, the University of Illinois Press inaugurates the Illinois Medieval Monographs - a major new series on life in medieval Europe.

\section{Edited and with an Introduction by Miguel Marciales}

Composed by Fernando de Rojas in Spain at the end of the fifteenth century, Celestina is considered by many to be the first modern novel and has. been cited as one of the four most important works in European literature, along with Hamlet, Faust, and Don Quixote. Yet, due to the proliferation of variant editions in numerous languages, no standard edition has until now been published.

Recognized as Marciales's magnum opus, this edition provides an exhaustive comparison of the three 16-act versions, the 1506 Italian translation, and some 23 editions prior to 1541 . He has, moreover, taken into account all manner of later versions and translations. Making literally thousands of textual choices to identify superior readings and showing how he arrived at those decisions, Marciales has clearly produced the definitive edition of one of the world's great literary treasures.

"The importance of Marciales's undertaking cannot be stressed enough. Establishing the critical text of any influential work of world literature must be a continuing priority of a literate society and Celestina is a case in point.

\begin{abstract}
Marciales's work can only be described as 'monumental' in scope and as a landmark in the clearing away of red herrings, false trails, and some overblown philological claims, all in the cause of clarity and reason. So scrupulous is Marciales to his texts, so adroit at making meaning from the slightest variant, that the whole becomes a dramatic, convincing reenactment of the life of Celestina-as-text." - Joseph Snow, editor, Celestinesca.
\end{abstract}

MIGUEL MARCIALES (1920?-1980) was for many years head of the department of classics at the University of Los Andes in Merida, Venezuela. Highly regarded among his colleagues and countrymen as a scholar, poet, and lecturer, Marciales devoted the last fifteen years of his life to producing this standard critical edition of Celestina.

Vol. I: 300 pages. $6 \times 9$ inches. March. ISBN 0-252-01200-3. $\$ 27.50$ s.

Vol. II: 300 pages. $6 \times 9$ inches. March. ISBN 0-252-01201-1.

$\$ 25.00$ s.

Both volumes are published in Spanish without translation.

\section{UNIVERSITY OF} ILLINOIS PRESS

54 E. Gregory Drive Champaign, Illinois 61820 (217) 333-0950

\section{Chicago Editorial Office}

\section{S.E.O.}

University of Illinois at Chicago Box 4348

Chicago, Illinois 60680

(312) 996-5080

\section{Book Ordering Information}

\section{WESTERN HEMISPHERE}

Trade and Library Orders

Harper \& Row Publishers, Inc.

Keystone Industrial Park

Scranton, Pennsylvania 18512

(800) 242-7737

in Pennsylvania (800) 982-4377

Individual Orders

University of Illinois Press

P.O. Box 1650

Hagerstown, Maryland 21741
UNITED KINGDOM

Harper \& Row, Ltd. 28 Tavistock Street London WC2E 7PN England

\section{CONTINENTAL EUROPE}

Harper \& Row Marketing Office 10 Lindelaan NL-1405 AK Bussum The Netherlands 